\title{
Generating Lies Produces Lower Memory Predictions and Higher Memory Performance Than Telling the Truth: Evidence for a Metacognitive Illusion
}

\author{
Miri Besken \\ Bilkent University and Heinrich-Heine Universität Düsseldorf
}

\begin{abstract}
Manipulations that induce disfluency during encoding generally produce lower memory predictions for the disfluent condition than for the fluent condition. Similar to other manipulations of disfluency, generating lies takes longer and requires more mental effort than does telling the truth; hence, a manipulation of lie generation might produce patterns similar to other types of fluency for memory predictions. The current study systematically investigates the effect of a lie-generation manipulation on both actual and predicted memory performance. In a series of experiments, participants told the truth or generated plausible lies to general knowledge questions and made item-by-item predictions about their subsequent memory performance during encoding, followed by a free recall test. Participants consistently predicted their memory performance to be higher for truth than for lies (Experiments 1 through 4), despite their typically superior actual memory performance for lies than for the truth (Experiments 1 through 3), producing double dissociations between memory and metamemory. Moreover, lying led to longer response latencies than did telling the truth, showing that generating lies is in fact objectively more disfluent. An additional experiment compared memory predictions for truth and lie trials via a scenario about the lie-generation manipulation used in the present study, which revealed superior memory predictions of truth than of lies, providing proof for a priori beliefs about the effects of lying on predicted memory (Experiment 5). The effects of the current lie-generation manipulation on metamemory are discussed in light of experience-based and theory-based processes on making judgments of learning. Theoretical and practical implications of this experimental paradigm are also considered.
\end{abstract}

Keywords: lying, memory, metamemory, fluency, bases of judgments of learning

No man has a good enough memory to be a successful liar.

-Abraham Lincoln

Self-report surveys indicate that $40 \%$ of all adults lie at least once a day (Serota, Levine, \& Boster, 2010). These lies may change in content, such as white lies (e.g., "You look beautiful in that dress"- - when she does not), denial of the truth (e.g., "I did not have sexual relations with that woman"-when he did), or generation of a plausible incorrect response (e.g., "I was at a work function"-when he or she was not). For both theoretical and applied reasons, reliable cues through which one can detect other people's lies have been widely examined (for a review, see DePaulo, Lindsay, Malone, Muhlenbruck, Charlton, \& Cooper, 2003)

This article was published Online First September 21, 2017.

Miri Besken, Department of Psychology, Bilkent University, and Mathematical and Cognitive Psychology, Institute of Experimental Psychology, Heinrich-Heine Universität Düsseldorf.

Miri Besken thank Mareike Groene, Lisa Raffelsieper, and Katja Wolff for their assistance in participant recruitment, data collection, and data coding as part of their senior thesis project requirement. Some portions of this research were orally presented at the Psychonomic Society's 56th Annual Meeting in Chicago, IL and at the 58th Conference of Experimental Psychologists TeaP in Heidelberg, Germany.

Correspondence concerning this article should be addressed to Miri Besken, Department of Psychology, Faculty of Economics, Administrative and Social Sciences, Bilkent University, Çankaya 06800, Ankara, Turkey. E-mail: mbesken@bilkent.edu.tr and typically reveal that liars appear less forthcoming, produce more disfluencies, and their stories are less compelling and include fewer imperfections. Most extant research has examined lying from the detectors' point of view (e.g., Bond \& Depaulo, 2006, 2008; Farah, Hutchinson, Phelps, \& Wagner, 2014; Hauch, Sporer, Michael, \& Meissner, 2016). However, lying may have many dire consequences for the liars themselves (Gneezy, 2005). Thus, it is critical to investigate lying from the liar's point of view. For a person who lies in a critical situation, remembering the content of the previous lies becomes quite important (Vieira \& Lane, 2013). For example, a culprit who has committed a crime and is trying to fabricate an alibi must lie consistently across cross-examinations and remember his or her lies accurately in order to avoid arrest. The current research focuses on three questions. First, how are people's memory for their truthful responses and self-generated lies? Second, as people generate these lies or tell the truth, how do they think their subsequent memory performance for these responses will be? Third, when participants predict their own subsequent memory performance for their responses, what are the underlying mechanisms of these predictions?

Lying can be operationally defined as the generation of incorrect information with the intention of deceiving others (Zuckerman, DePaulo, \& Rosenthal, 1981). Most research that examines the memory of generation of incorrect information comes from forced confabulation and false memory research. Typically, participants witness a critical event and are asked to confabulate information about it in a postquestionnaire (e.g., participants may be asked to indicate where the victim was bleeding, even though the victim has 
not bled at all), followed by a memory test for the original event (e.g., Zaragoza, Payment, Ackil, Drivdahl, \& Beck, 2001). For those participants who are asked to confabulate information, the free recall of the incorrect information is higher, compared with the control group (e.g., Chrobak \& Zaragoza, 2008, 2013; Zaragoza, Mitchell, Payment, \& Drivdahl, 2011). Most of these studies assume that participants usually try to tell the truth, yet their memory is distorted by later suggestions or forced confabulations (e.g., Lane \& Zaragoza, 2007). Yet, in real life, sometimes witnesses lie intentionally. However, very few studies have examined the effects of deliberate lying on subsequent memory performance (for a few exceptions, see Colwell et al., 2011; Pickel, 2004; Polage, 2004, 2012; Otgaar, Howe, Memon, \& Wang, 2014; Vieira $\&$ Lane, 2013) The very few studies that investigated the effects of deliberate lying on memory reveal that the incorrect generated plausible information can sometimes be remembered more or at the same rate, as compared with a control group or control condition (Vieira \& Lane, 2013; Pickel, 2004). For example, Pickel (2004) showed that participants who were deliberately asked to fabricate details about a perpetrator in a video remembered more incorrect details and less correct details than the control group. Similarly, Vieira and Lane (2013) found that when participants generated incorrect information as a plausible alternative to the truth at encoding, they recognized the source just as well for the generated incorrect information as they did for the generated truthful responses in a source recognition test.

Theoretically, the higher memory performance for generating lies than telling the truth is not surprising, considering the increased cognitive processes involved in generating lies. First, lying generally takes a longer time than telling the truth (Verschuere, Spruyt, Meijer, \& Otgaar, 2011; Vrij et al., 2008; Walczyk, Mahoney, Doverspike, \& Griffith-Ross, 2009; Walczyk, Roper, Seeman, \& Humphrey, 2003; Williams, Bott, Patrick, \& Lewis, 2013). Second, lying is cognitively more demanding than telling the truth (Gombos, 2006; Vrij, Fisher, Mann, \& Leal, 2006). For instance, liars display more speech hesitation and speak at a slower rate when their cognitive load is increased (Vrij et al., 2008) and perform poorer in secondary tasks when lying than when telling the truth (Hu et al., 2015). Moreover, neural correlates of deception suggest that participants show significantly more activity in the anterior cingulate cortex and the dorsolateral prefrontal cortex - areas frequently associated with executive functions, such as response inhibition and cognitive control-when lying than when telling the truth (Langleben et al., 2002; Mohamed et al., 2006). Last, different theoretical models of deception typically contend that lying involves several extra phases than does telling the truth. For example, activation-decision-construction model asserts that lying includes additional phases, such as suppression of the truth, decision to lie, and construction of the lie (Williams et al., 2013; Walczyk et al., 2003; Walczyk, Harris, Duck, \& Mulay, 2014). Similarly, working memory models of deception suggest that generating lies requires participants to inhibit their responses, which in turn increases the workload associated with lying as a result of the need to modify a truthful answer into a deceptive one (Sporer, 2016; Vendemia, Buzan, \& Simon-Dack, 2005). Because lying takes longer, requires more cognitive resources, and involves several extra phases, it can be considered more effortful than telling the truth.
Generating lies could also be considered as a unique instance and extension of the classic generation effect, which indicates that self-generated information leads to higher memory performance than passive reading (Slamecka \& Graf, 1978). Pickel (2004) showed that both self-generated and other-generated instances of misinformation in eyewitness testimony are recalled at higher rates than correct information in a subsequent memory test. Similarly, Lane and Zaragoza (2007), using a similar design, showed that false memories are integrated more into the original event through suggestibility when participants have to generate the details about the event later on. Thus, more effortful processing (Hasher \& Zacks, 1979; Hintzman, 2011; McDaniel \& Bugg, 2008) and self-generation of responses (Bertsch, Pesta, Wiscott, \& McDaniel, 2007; Mulligan \& Lozito, 2004) typically leads to better memory performance. Accordingly, more effortful generation of lies might enhance their mnemonic benefits in a subsequent memory test. One goal of the current research is to assess whether generating lies produces better memory as compared with telling the truth on a free recall test.

Because lying is associated with longer latencies, higher cognitive resource demands, and is hypothesized to involve extra phases, it might also be considered less fluent than is telling the truth. It has been shown that fluency, "the subjective experience of ease or difficulty associated with completing a mental task" (Oppenheimer, 2008, p. 237) affects a wide array of judgments (Alter \& Oppenheimer, 2009; Oppenheimer, 2008). The impact of fluency has been widely shown in the area of metacognitive judgments of learning (JOLs; see Rhodes, 2016 for a general review), which evaluates participants' confidence at encoding that they will remember an item in a subsequent test. Typically, more fluently processed, retrieved, or perceived items receive higher JOLs, as compared with disfluent items. For example, when some items are processed more fluently than are other items, as measured by self-paced study times or subjective evaluations of the stimuli, they receive higher JOLs as compared with slowly processed items (Begg, Duft, Lalonde, Melnick, \& Sanvito, 1989; Hertzog, Dunlosky, Robinson, \& Kidder, 2003). Similarly, if it takes a longer time for participants to retrieve answers from semantic memory, as measured by retrieval latency, participants predict that they will remember these items less, despite their superior actual memory performance than easily retrieved answers (Benjamin, Bjork, \& Schwartz, 1998; Kelley \& Lindsay, 1993; Koriat \& Ma'ayan, 2005; Winkielman, Schwarz, \& Belli, 1998). Finally, if an item is easier to perceive at encoding, measured through identification speed or subjective ease of processing, it receives higher JOLs for subsequent memory performance, compared with items that are difficult to perceive, despite the fact that perception does not always affect actual memory performance (Besken, 2016; Besken \& Mulligan, 2013, 2014; Rhodes \& Castel, 2008, 2009; Yue, Castel, \& Bjork, 2013). In this way, lie generation might also produce results similar to the other fluency variables discussed in the preceding text, because generating lies takes longer, requires more mental effort and involves several additional phases than telling the truth; thus, it is objectively more disfluent, and may lead to lower JOLs for lies than the truth.

In contrast to the fluency research, some research has also shown that self-generation may influence JOLs positively, specifically if the participants believe that self-generation is useful to memory. For example, participants produce higher JOLs for items 
that they read loudly compared with items that they read silently (Castel, Rhodes, \& Friedman, 2013). Similarly, if participants generate some words from a word-fragment at encoding while passively reading others, the generated information leads to higher JOLs than does passively read information, despite the finding that actual memory performance may not always be affected by this manipulation (Begg, Vinski, Frankovich, \& Holgate, 1991). In the current paradigm, because participants are putting more effort into lie generation than into telling the truth, they might also believe that they will remember their lies better than they will the truth. A second goal of the current research is to assess how lie generation affects JOLs. If participants are asked to produce truthful responses to some questions and generate lie responses to other ones, fluency research predicts generating lies should also produce lower JOLs as compared with telling the truth, when participants predict their subsequent memory performance at encoding, because of increased difficulty associated with producing lies. On the contrary, participants might believe that generating is good for memory performance, which is in line with the findings from the production manipulation (Castel et al., 2013) and from certain generation manipulations (Begg et al., 1991); consequently, participants could predict that they should produce higher JOLs for the lie trials than for the truth trials because of the benefits of self-generation.

The current project investigated the relationships among lying, memory, and metamemory through five experiments. One goal of the project was to investigate how generating lies affects both memory and memory predictions. In the first four experiments, participants were asked to tell the truth and to generate plausible lies from the same category to general knowledge questions in a mixed list, followed by judgments of learning about their predictions to remember their responses in a subsequent memory test. After a brief distractor, participants were asked to free recall their answers from the encoding phase. This was followed by an experimental manipulation check wherein participants answered all the general knowledge questions correctly.

For the first two experiments, an ecologically valid design was implemented such that participants generated their own responses either at a self-paced speed (Experiment 1) or an experimenterpaced speed (Experiment 2). In Experiment 3, participants were provided with appropriate experimenter-generated word-stems for both truth and lie responses, which they had to complete accordingly. Experiment 3 had two main goals: (1) to reduce participants' effort in generating the responses in both truth and lie trials to examine its impact on memory and metamemory and (2) to eliminate item selectivity issues that might occur with self-selected responses, specifically for lies. In Experiment 4, participants were prompted to choose the appropriate answer from a two-choice test. This was done to reduce the effortful processing even further and to see its impact on both memory predictions and memory. The current paradigm operationalizes lying as the generation of incorrect responses to general knowledge questions. It is important to point out that this operationalization may not mimic lying as it occurs in real-life, though it is similar to many experimental lie-production paradigms that do not use high-stakes, goaldirected, emotion-involved, episodic, and personal questions but instead focus on the underlying cognitive mechanisms of lying (e.g., Vieira \& Lane, 2013; Williams et al., 2013). The use of general knowledge questions in lie generation makes it easier to assert control over the experimental materials and might produce an advantage in determining the underlying cognitive bases, rather than the emotional bases of lying.

In the current design, generating lies should generally lead to higher free-recall performance paired with lower memory predictions for lies than for truth, creating a double dissociation with opposite effects on actual and predicted memory. This should constitute compelling evidence for the presence of a metacognitive illusion because double dissociations are theoretically more constraining than are single dissociations and more difficult to attribute to a single underlying process (Berry, Shanks, \& Henson, 2008; Dunn \& Kirsner, 1988).

In all of the present experiments, participants predicted that they would remember their truthful responses better than their lies. Thus, generating lies operates similarly to other variables of fluency, with the more disfluent lying condition producing lower JOLs than the more fluent truth condition. However, it is not clear as to why the more disfluent lying condition might affect memory predictions this way. Theoretically, two different sources of information are hypothesized to contribute to this difference between fluent and disfluent items: nonanalytic, experience-based processes and analytic, theory-based processes (Koriat, Bjork, Sheffer, \& Bar, 2004; Matvey, Dunlosky, \& Guttentag, 2001). Nonanalytic, experience-based processes refer to the online subjective difficulties that participants experience while they process the critical items. For example, if participants spend more time and effort generating the lie response than the truthful response, and their JOLs are affected directly from this experienced difficulty, this is an indication of the contribution of experience-based processes to JOLs. Analytic, theory-based processes, on the other hand, refer to a priori beliefs or beliefs that are formed during the experiment about the effects of a manipulation on subsequent memory performance. For example, if participants have a priori belief that the truth will be remembered better than the lies, they might be compelled to give higher JOLs to the truthful responses than to the lie responses. This type of a finding constitutes evidence for the effect of theory-based processes on JOLs. A third goal of the current set of studies was to assess the contribution of experience-based and theory-based processes to decreased JOLs for the generated lies. Experiments 1 through 4 used response latency as an indication of fluency in experience-based processes and assessed whether experience-based processes mediate the relationship between the manipulation and the memory predictions. Experiment 5 tested the a priori beliefs of participants unfamiliar with the paradigm by presenting them with the scenario used in Experiment 2 and asking them to make memory predictions without exposure to the actual experiment.

\section{Experiment 1}

In Experiment 1, participants were presented with general knowledge questions from different categories, to half of which they responded with the truth, and to the rest with a plausible lie from the same category. For each response, they were asked to make an immediate JOL, indicating their confidence that they would remember their own response in a later memory test. This phase was followed by a short distraction phase and a free-recall phase in which they recalled their responses from the first phase. Last, participants were presented with a truth-check phase in which 
they were asked to respond to all questions from the encoding phase truthfully, ensuring that they knew the correct answers to the questions.

The first goal was to determine whether generating lies produces higher free recall performance than does telling the truth. If generating lies at encoding leads to more effortful processing, then participants' performance for the free recall of self-generated lies should be higher than their free recall of truthful responses.

The second goal of the experiment was to determine how this lie-generation manipulation affects item-by-item JOLs. If the liegeneration manipulation is conceived as a more effortful and a less fluent process, the more fluent truth condition should produce higher JOLs than the less fluent lie-generation condition. In this case, the lie-generation manipulation should produce a double dissociation between memory and metamemory such that lie generation increases free recall while decreasing the JOLs.

The third goal of the experiment was to see whether onset of the response and the duration of typing for the conceptually more difficult lie-generation condition were in fact objectively slower than the truthful response condition. During the experiment, participants were asked to type in their responses as soon as they generated an appropriate answer. The program recorded participants' latency for first keypress and response completion: If the lie-generation condition is indeed more effortful than is the truthtelling condition, it should produce slower response latencies as measured by first keypress latency and response completion latency.

Last, the experiment sought to determine the contribution of experience-based and theory-based processes to the current manipulation. Because the theory-based and experience-based processes might contribute to JOLs, the correlations between item type (e.g., disfluent vs. fluent items) and item-by-item JOLs are hypothesized to represent the contribution of both effects. To determine the independent contribution of experience- and theorybased processes on JOLs, researchers typically measure the latency to identify, respond, perceive, or retrieve an item, which is considered as an index of objective experience-based processes, and investigate whether this response latency mediates the relationship between item type and JOLs (e.g., Besken \& Mulligan, 2014; Besken, 2016; Mueller, Dunlosky, \& Tauber, 2016; Mueller, Dunlosky, Tauber, \& Rhodes, 2014; Undorf \& Erdfelder, 2015). In the current and all subsequent experiments, the relationship between encoding condition (truth trials vs. lie trials), response latency, and JOLs was investigated through the use of mediational analyses at item and participant levels through multilevel modeling. If only experience-based processes directly affect JOLs, then the response latency should mediate the relationship between item type and JOLs completely. If only theory-based processes are influential in making JOLs, the response latency should not mediate the relationship between item type and JOLs. Alternatively, response latencies may partially mediate the relationship between item type and JOLs, implying independent contributions of both experienceand theory-based processes to memory predictions at encoding.

\section{Method}

Participants. Thirty-three native speakers of German between the ages of 18 and 35 from the Heinrich-Heine-Universität (Düsseldorf) community participated in the experiment. They were compensated with either course credit or a payment of $€ 3$. A statistical power analysis was performed for sample size estimation through G-power (Faul, Erdfelder, Buchner, \& Lang, 2009) based on data from a pilot study comparing the free recall performance for lie generation to truth-telling condition, producing an effect size of .60. The power of a sample size of 32 is to detect an effect of that size $(n=32, \alpha=.05$, one-tailed $)$ is .95. In accordance with the institutional review board regulations of Heinrich-Heine Universität Düsseldorf, this study was exempt from review.

Materials and design. The encoding condition (truth trials vs. lie trials) was manipulated within subjects. The general knowledge questions to be used in the experiment were created by the experimenter. Each question came from a different category, primarily chosen from the categories of Van Overschelde, Rawson, and Dunlosky (2004), taking into consideration German participants' familiarity with the categories. The items were piloted to ensure that the correct response to each question was identified by a majority of pilot participants. The final material consisted of 32 critical questions from different categories, along with two practice items at the beginning of the encoding phase to clarify the procedure, adding up to a total of 34 items for the encoding phase. A copy of the critical questions is presented in Appendix A.

For a given encoding list, the general knowledge questions were randomly assigned to the truth or lie condition. Two versions of the encoding list that counterbalanced the questions across encoding conditions were presented to an equal number of participants. The order of the critical questions was randomized for each participant such that no more than two questions from the same encoding condition were presented consecutively. Practice items were excluded from all analyses.

Procedure. Participants were tested on individual computers either alone or in groups of two to four. The experiment consisted of four phases: encoding phase, distractor phase, testing phase, and truth-check phase. All the instructions were presented on the screen. The experimenter answered questions if there were any.

The experiment started with the encoding phase. Participants were given on-screen instructions indicating that they would be presented with general knowledge questions and that they would need to answer half of the questions with truthful responses and the rest of the questions with a plausible lie from the same category as the truthful response. They were told that they would have to retrieve their own responses to the questions for both truth and lie trials. No further information was provided about the nature of the memory test. They were given examples of truth and lie responses for one question in the instructions and two practice questions and were instructed that they should type $X X$ if they did not know the truthful answer for the question on the screen. All the trials were self-paced.

For truth trials, participants were first presented with the prompt "Truth" (Wahrheit in German) and asked to press $W$ to proceed. This ensured that participants paid attention to the type of response that they needed to provide. Pressing $W$ initiated the display of the question on the screen underneath the prompt. Participants typed in their response and pressed the ENTER key to proceed to the JOL screen. The program recorded participants' first keypress latency (the time that elapsed from the appearance of the question to the time participants pressed a key) and response completion latency (the time that elapsed from first keypress to the time they 
pressed the ENTER key). Participants were asked to type their responses rather than responding verbally to enable group testing, randomization of trial order, and accurate measurement of response latency. Response latency in the form of first keypress latency and response completion latency has been used as an index of retrieval fluency in previous research (e.g., Serra \& Dunlosky, 2005). On the next screen, participants were asked to make a self-paced JOL rating and indicate their confidence that they would remember their own response in a later memory test on a scale from 0 (not confident at all) to 100 (extremely confident). As participants could type any number between 0 and 100, JOLs were on a continuous scale.

For lie trials, the procedure was very similar. Participants were presented with the prompt "lie" (Luge in German) and were asked to press 1 to proceed. Pressing 1 initiated the display of a question, to which participants typed in a plausible lie from the same category as the truthful response, and pressed the ENTER key, which was followed by a self-paced JOL for each trial.

After the encoding phase, participants were given a 3-min distractor task in which they solved arithmetic problems presented on the computer screen one at a time. The free-recall test followed the distractor phase. Participants were asked to recall and type in as many of their own responses as possible from both truth and lie trials. Once they typed in the response and pressed the ENTER key, they could see their response on the screen and could proceed onto typing the next one. The time limit for the recall phase was 5 min, but it could also be self-terminated earlier by pressing the ESC key.

In the truth-check phase, participants were presented with all the general knowledge questions from the encoding phase again, and were asked to type in the correct response for all questions. This was done to ensure that the participants knew the correct response to the questions. This check provides more precise information about participants' knowledge about the questions and a more accurate estimation of the participants' performance at both encoding and recall phases.

\section{Results and Discussion}

Response latencies, metamemory, and memory. All descriptive statistics for Experiment 1 are presented in Table 1. For all analyses, the alpha level was set at .05. To be included in the analyses for this experiment and all subsequent experiments, participants must have followed the procedure at least $80 \%$ of the time for both truth and lie trials. The criteria for coding the responses and the compliance to procedure are available in Appendix B. One participant was excluded from further analyses for not having followed the procedure at the preset level and was replaced with another participant in the same condition, leaving an effective number of 32 participants. During the encoding phase, participants' rates for following the procedure for both truth trials (96.88\%) and lie trials $(97.06 \%)$ were quite high. A sign test revealed that participants' compliance to the procedure did not significantly differ across the two encoding conditions $(p=1.00)$.

For encoding, the median latencies (response times [RTs]) for the first keypress and the total typing time were calculated for each participant separately for truth and lie trials, excluding the trials in which participants did not follow the procedure for this and all subsequent experiments (exclusion rate $=3.02 \%$ ). The mean of median latencies for these two encoding conditions were submitted to a paired-samples $t$ test, showing that it had a significant effect on first keypress latency, $t(31)=5.88, p<.001, d=1.04$, and on response completion latency, $t(31)=3.62, p<.001, d=.64$. Participants took longer to initiate and to complete the responses in lies trials than the truth trials.

For item-by-item JOLs, trials in which participants did not follow the procedure or failed to type in their JOLs were excluded (3.22\%) for this and all subsequent experiments. A paired-samples $t$ test showed that participants predicted to remember their truthful responses more than their self-generated lies, $t(31)=4.36, p<$ $.001, d=.77$.

High rates for following procedure at encoding make it possible to analyze recall data without conditionalizing it on compliance to the procedure at encoding. Because unconditional and conditionalized recall produce the same results, only unconditional inferential tests are reported for the recall data in this and all subsequent experiments. The scoring procedure for unconditional and conditionalized recall data is explained in Appendix B. A pairedsamples $t$ test showed that participants recalled their self-generated lies significantly more often than their truthful responses, $t(31)=$ 4.31, $p<.001, d=.77$.

The correct response rate for truth-check phase was quite high for both truth $(98.63 \%)$ and lie $(97.69 \%)$ conditions, and was not significantly different across encoding conditions by a sign test $(p=.581){ }^{1}$

Measures of resolution. For Goodman-Kruskal gamma correlations, trials in which participants did not follow the procedure or failed to type in their JOLs were excluded (3.22\%) for this and all subsequent experiments. The mean Goodman-Kruskal gamma correlation for the truth trials was $.27(S D=.59)$ and was significantly different than 0 in a one-sample $t$ test, $t(24)=2.31, p=$ $.030, d=.46 .^{2}$ The mean gamma correlation for the lie trials was $.09(S D=.41)$, and was not significantly different than 0 in a one-sample $t$ test, $t(30)=1.16, p=.257, d=.21$. A pairedsamples $t$ test revealed no significant differences across the two encoding conditions, $t(24)=1.22, p=.234, d=.24$.

Mediational analyses. To examine whether JOLs for the current lie-generation manipulation was mediated by the objective measures of fluency (e.g., first keypress latency or response completion latency), first multilevel regression analyses were conducted, using the R statistical package lme4 (Bates, Maechler, Bolker, \& Walker, 2015; R Core Team, 2013). Of the total number of trials, $3.22 \%$ were excluded from the analyses, either because the participants did not follow the procedure for the trial or because they did not enter their JOLs for those trials. First keypress latency and response completion latency were natural-log trans-

\footnotetext{
${ }^{1}$ Two participants misunderstood the instructions for the truth-check phase and responded to questions with the answers they provided at encoding phase rather than the correct responses to the questions. For this and all subsequent experiments, the responses in the lie condition were excluded from the truth-check analyses for the participants who misunderstood the instructions in the truth-check phase. These participants were treated as if they responded to all lie questions correctly at truth-check phase for encoding and the conditional recall analyses.

${ }^{2}$ Gamma correlations were not calculated for 7 participants in truth trials and 1 participant in lie trials, as these participants always produced the same JOLs for the condition or they failed to remember any words from one of the conditions.
} 
Table 1

Means and Standard Error of the Mean (in Parentheses) for First Keypress Latency, Response Completion Latency, Memory Predictions, and Unconditional Proportion Correct Recall for Experiments 1 Through 4

\begin{tabular}{|c|c|c|c|c|c|c|c|c|}
\hline \multirow[b]{2}{*}{ Experiment } & \multicolumn{2}{|c|}{ First keypress (in ms) } & \multicolumn{2}{|c|}{ Response completion (in ms) } & \multicolumn{2}{|c|}{$\begin{array}{l}\text { Memory predictions } \\
\text { (out of 100) }\end{array}$} & \multicolumn{2}{|c|}{$\begin{array}{l}\text { Unconditional } \\
\text { proportion correct } \\
\text { recall }\end{array}$} \\
\hline & Truth & Lie & Truth & Lie & Truth & Lie & Truth & Lie \\
\hline 1 & $3,592.06(146.08)$ & $5,144.30(311.88)$ & $2,852.53(136.11)$ & $3,698.03(255.77)$ & $82.43(3.26)$ & $66.93(4.14)$ & $.33(.02)$ & $.47(.03)$ \\
\hline 2 & $3,019.16(99.70)$ & $3,856.20(145.12)$ & 2,176.84 (89.90) & $2,528.59(134.97)$ & $85.75(2.84)$ & $65.56(3.06)$ & $.36(.02)$ & $.45(.02)$ \\
\hline 3 & $2,761.94(101.67)$ & $3,215.86(114.28)$ & $1,378.75(91.40)$ & $1,625.91(125.23)$ & $87.00(2.57)$ & $69.53(3.13)$ & $.33(.03)$ & $.46(.02)$ \\
\hline 4 & $3,775.14(143.31)$ & $3,823.34(160.80)$ & & & $86.21(2.50)$ & $73.86(4.11)$ & $.28(.02)$ & $.32(.03)$ \\
\hline
\end{tabular}

Note. Only first keypress latencies are displayed for Experiment 4 because the encoding manipulation only requires a single keypress.

formed to normalize the response latency data. Two mixed linear models (Level 1: items; Level 2: participants) with participants as random effects, and encoding condition and latency as fixed effects were fitted separately for both dependent measures. In the first model, latency was regressed on encoding condition; in the second model, JOLs were regressed on encoding condition and latency. See the upper portion of Figure 1 for the unstandardized coefficients for direct effects of encoding condition on latency and the direct effects of encoding condition and latency on JOLs for first keypress latency (see Panel A) and response completion latency (see Panel B) for Experiment 1.

Mediation analyses were carried out using the R package mediation (Tingley, Yamamoto, Hirose, Keele, \& Imai, 2014; for underlying methods, see Imai, Keele, \& Tingley, 2010). The indirect effects of lie generation on JOLs mediated by first keypress latency and their $95 \%$ CIs were estimated through the Tingley et al. (2014) nonparametric bootstrapping procedure with 5,000 bootstrap samples for this and all following experiment. The estimates of the unstandardized regression coefficients and their 95\% CIs for both direct and indirect effects through causal mediational analyses are displayed in a table in the lower portion of Figure 1, for both first keypress latency (see Panel A) and response completion latency (see Panel B). For first keypress mediational analyses, the direct effect of lie generation on JOLs was 13.91, (95\% CI [11.59, 16.35], $p<.001)$. The indirect effect of lie generation on JOLs through first-keypress latency was 1.34 , $(95 \%$ CI [0.43, 2.28], $p<.001)$. The proportion of the total effect of encoding condition on JOLs mediated by first keypress latencies was $0.09,(95 \%$ CI $[0.03,0.15], p<.001) .^{3}$

For response completion latency, the direct effect of lie generation on JOLS was 15.06, (95\% CI [12.77, 17.37], $p<.001)$. The indirect effect of lie generation through response completion latency was .22 and not significant (95\% CI [-.28, .73], $p=.39$ ). The proportion of the total effect of encoding condition on JOLs mediated by response completion latency was 0.01 and not significant $(95 \%$ CI $[-0.02,0.05], p=.39)$.

In sum, the mediation analyses revealed that both direct and indirect effects of the lie-generation manipulation on JOLs were significant. This suggests that the objective measures of fluency for generating a truthful response or a lie response, as measured by first keypress latency, partially mediates the effects of lie generation on JOLs. Response completion latency, another objective measure of fluency, did not mediate the effect, showing that not all measures of fluency are associated with experience-based pro- cesses. First keypress might be a better indicator of fluency: Once the participants generate the appropriate response, the time that it takes to complete the response might be irrelevant (Besken, 2016).

The current experiment shows that when participants are asked to provide truthful responses or self-generated lie responses to general knowledge questions, they predict their memory performance to be higher for truthful responses, despite their higher memory performance for the lies than for the truth. In other words, the lie-generation manipulation produces opposite effects on memory predictions and actual free recall performance, which provides evidence for the presence of separate underlying mechanisms for memory and metamemory. This double dissociation produces more concrete proof for the separability of the mechanisms as compared with dissociations in single measures (Berry et al., 2008; Dunn \& Kirsner, 1988) and constitutes solid evidence for a metacognitive illusion.

Additionally, lying took longer than did telling the truth for both initiation and completion latency of responses, which shows that lying is objectively less fluent, as has been found in previous lying manipulations (Verschuere, Spruyt, Meijer, \& Otgaar, 2011; Vrij et al., 2008; Walczyk, Mahoney, Doverspike, \& Griffith-Ross, 2009; Walczyk, Roper, Seeman, \& Humphrey, 2003; Williams, Bott, Patrick, \& Lewis, 2013). More importantly, as expected, the less fluent self-generated lie condition produced lower JOLs than did the more fluent truthful response condition, which is consistent with other fluency manipulations, such as encoding fluency (Begg et al., 1989; Hertzog et al., 2003), retrieval fluency (Benjamin et al., 1998), and perceptual fluency (Besken, 2016; Besken \& Mulligan, 2013, 2014; Rhodes \& Castel, 2008, 2009). Mediational analyses revealed that at least one of the two objective measures of fluency, first keypress latency, partially mediates the effect of the lie-generation manipulation effect on JOLs: The response completion latency did not mediate the effect, showing that not every type of latency affects JOLs to the same extent. When participants have difficulty in generating incorrect responses, it is reflected in their predictions for their subsequent memory performance, which, for the lie-generation paradigm, implies a

\footnotetext{
${ }^{3}$ For this and all subsequent analyses, the direct effects encoding condition on JOLs yield slightly different results between the regression analyses and the causal mediational analyses because mediational analyses report the estimates of the direct and indirect effects through a nonparametric bootstrapping procedure.
} 
A

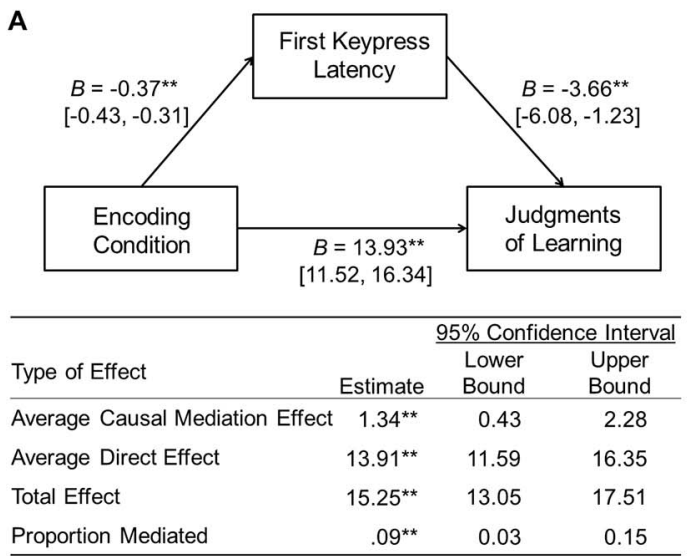

B

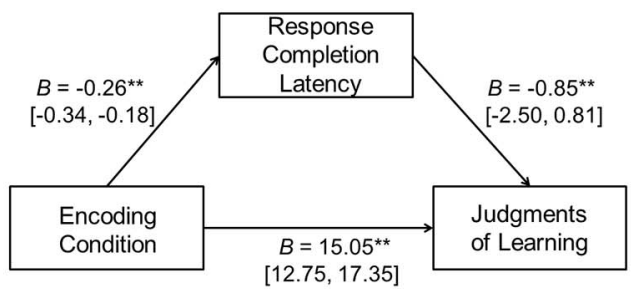

\begin{tabular}{lccc}
\hline & \multicolumn{3}{c}{$95 \%$ Confidence Interval } \\
\cline { 3 - 4 } Type of Effect & Estimate & Upper \\
& Bound & Bound \\
\hline Average Causal Mediation Effect & 0.22 & -0.28 & 0.73 \\
Average Direct Effect & $15.06^{\star *}$ & 12.77 & 17.37 \\
Total Effect & $15.28^{\star *}$ & 13.07 & 17.51 \\
Proportion Mediated & .01 & -0.02 & 0.05 \\
\hline
\end{tabular}

Figure 1. Experiment 1 unstandardized regression coefficients (95\% confidence intervals [CIs]) for the direct effects of encoding condition on latency and for the direct effects of encoding condition and latency on judgments of learning, separately, for first keypress latency (Panel A) and response completion latency (Panel B). The complementary tables below each figure show. The estimates of the unstandardized regression coefficients and their 95\% CIs for direct, indirect (average causal mediation effect), total effect, and the proportion of mediation for each causal mediation analysis. ${ }^{* *} p<.01$.

role for experience-based processes in JOLs. Obviously, this objective measure of fluency only partially mediates the relationship between encoding condition and JOLs. If JOLs represent the contribution of experience-based and theory-based processes when the effects of objective fluency measures are taken out, the remainder of the effects might also imply a role for theory-based processes. This is discussed further in Experiment 5 and the General Discussion.

\section{Experiment 2}

Experiment 1 revealed that the lie-generation manipulation produces opposite effects on memory and metamemory such that participants predicted that they would remember their truthful responses more than their lie responses, despite their superior memory performance for the lies. However, in Experiment 1 , the self-paced encoding phase allowed participants to take as much time as they wanted to generate a response to the questions. Because the lie trials generally took more time, on average, than did the truth trials, both the superior memory performance and the lower metamemory predictions for the lies might be a consequence of longer self-paced durations for them, which constitutes a confound. Experiment 2 aimed to eliminate this confound by using experimenter-paced study times. If the lie-generation manipulation requires greater mental effort than does telling the truth, the lies should produce higher memory and lower metamemory predictions, even when the participants have equivalent time to generate and study their truthful and lie responses.

\section{Method}

Participants. Thirty-two native speakers of German between the ages of 18 and 35 from Heinrich-Heine-Universität participated in the experiment. They were compensated with either course credit or a payment of $€ 3$.
Design, materials, and procedure. The design and materials were identical to those used in Experiment 1. Experiment 2 differed from Experiment 1 in that each general knowledge question was presented for a total of $12 \mathrm{~s}$. Participants were again presented with the prompts "truth" and "lie," and once they responded with the correct keypress, they proceeded to the question. Participants were told that once they saw the question, they had to write their truthful or lie response as quickly as possible and press the ENTER key once they finished typing. As soon as participants pressed the ENTER key, the background turned gray and the participants were not allowed to modify their responses. The program recorded first keypress and response completion latencies. The program moved onto the JOL-screen $12 \mathrm{~s}$ after the onset of the question, regardless of whether the participant had completed his or her typing. JOLs were self-paced as in Experiment 1. The distractor, the testing phase, and the truth-check phase were identical to those used in Experiment 1.

\section{Results and Discussion}

Response latencies, metamemory, and memory. The descriptive statistics for Experiment 2 are presented in Table 1. All participants were able to fulfill the preset criteria of following the procedure $80 \%$ of the time in both truth and lie trials and, thus, were included in the analyses. For encoding, participants followed the procedure $95.11 \%$ of the time for truth trials and $93.35 \%$ of the time for the lie trials. A sign test revealed that the compliance to procedure was not significantly different across the encoding conditions $(p=.38)$.

The total number of trials $(5.76 \%)$ in which participants did not follow the encoding procedure correctly were excluded from the response latency analyses. A paired-samples $t$ test revealed that participants' first keypress for the truth trials was significantly faster than for the lie trials, $t(31)=7.92, p<.001$, $d=1.40$. Response completion latency was also significantly 
faster in the truth trials than in the lie trials, $t(31)=3.17, p=$ $.003, d=.56$.

Participants were more confident in their JOLs for truth trials than for lie trials, $t(31)=6.62, p<.001, d=1.17$ (exclusion rate for JOL analyses $=7.32 \%$ ), despite their better free recall performance for lie trials than for truth trials, $t(31)=3.13, p=.004, d=$ .55 . The correct response rates in the truth-check phase were quite high for both truth $(98.25 \%)$ and lie $(96.88 \%)$ conditions and did not significantly differ by a sign test $(p=.607){ }^{4}$

Measures of resolution. For Goodman- Kruskal gamma correlations, trials in which participants did not follow the procedure or failed to type in their JOLs were excluded (exclusion rate $=$ $7.32 \%)$. The mean gamma correlation for the truth trials was -.07 $(S D=.58)$, and was not significantly different than 0 in a onesample $t$ test, $t(27)=.61, p=.549, d=.11 .^{5}$ The mean gamma correlation for the lie trials was $.22(S D=.42)$ and was significantly different than 0 in a one-sample $t$ test, $t(31)=2.96, p=$ $.006, d=.52$. The paired-samples $t$ test that compared gamma correlations across conditions revealed that participants had significantly higher resolution for lie trials than for truth trials, $t(27)=2.53, p=.018, d=.48$.

Mediational analyses. Because they did not follow the correct encoding procedure or failed to type in their JOLs, $7.32 \%$ of the trials were excluded from the analyses. The upper portion of Figure 2 shows the unstandardized coefficients and their 95\% CIs for direct effects of encoding condition (trial type: lie trials $=0$, truth trials $=1$ ) on latency and the direct effects of encoding condition and latency on JOLs, separately, for first keypress (see Panel A) and response completion latency (see Panel B) for Experiment 2.

Figure 2 also shows the estimates of the causal mediation analyses for direct effects, indirect effects, total effects, and the total proportion mediated, separately, for first keypress latency (see Panel A) and response completion latency (Panel B). For first keypress mediational analyses, the direct effect of lie generation on JOLs was 17.75, (95\% CI [15.22, 20.32], $p<.001)$. The indirect effect of lie generation on JOLs through first keypress latency was 2.32, (95\% CI [1.46, 3.27], $p<.001)$. The proportion of the total effect of encoding condition on JOLs mediated by first keypress latencies was 0.12, (95\% CI [0.07, 0.17], $p<.001)$.

For response completion latency, the direct effect of lie generation on JOLs was 19.63, (95\% CI [17.19, 22.11], $p<.001)$. The indirect effect of lie generation through response completion latency was $.41,(95 \% \mathrm{CI}[.05, .86], p=.02)$. The proportion of the total effect of encoding condition on JOLs mediated by response completion latency was 0.02 , (95\% CI [0.003, 0.04], $p=.02)$.

As in Experiment 1, the lie-generation manipulation produced opposite effects on predicted and actual memory, with lower JOLs and higher free recall performance for lie trials than for truth trials. This result was obtained, even when the latency to produce and study the responses for both truth trials and lie trials was kept constant. This suggests that the effect is not an artifact of longer encoding durations for the lie trials, but it is rather a consequence of increased mental effort for generating the lie responses. In Experiment 2, both measures of fluency partially mediated the relationship between the manipulation and the memory predictions, denoting a role for experience-based processes in evaluating predictions of subsequent memory performance.

\section{Experiment 3}

Experiment 2 shows that even when participants are given an equal amount of time to produce both truth responses and lie responses, they believe that they will remember more of their truth responses than their lie responses, despite the higher free recall performance for the lie responses. Perhaps if participants put less effort into producing these responses in general, the decreased JOLs for the lie-generation manipulation might be eliminated. Thus, in Experiment 3, participants were presented with the word stems to both truth and lie questions. In a mixed-list design, participants were asked to complete the word stems with truthful responses for the truth trials and with an incorrect response from the same category for the lie trials. Both types of responses were predetermined by the experimenter. If the lie trials produce more disfluency than do the truth trials, despite the fact that less effort is involved in the truth trials, then this should be reflected in the first keypress latency and response completion latency. Moreover, participants should have less confidence in remembering the lies than in remembering the truth. Because it requires more effort for participants to encode the lies, the lie trials should produce higher free recall performance than should the truth trials.

Experiments 1 and 2 made use of freely generated truth and lie responses for ecological validity purposes and because it is important to assess freely generated lie responses. However, the generation of the lies might lead to some item selection issues. In particular, for the general knowledge questions, items that are chosen for lie generation might be easier to recall than might items that are for the correct response. Moreover, participants may put more mental effort into encoding the items that are more difficult to process (Thiede \& Dunlosky, 1999). The use of word stems in Experiment 3 ensures that the items are not more memorable because of self-selected item bias in the subsequent memory test. This modification exerts more control over the current experimental manipulation.

\section{Method}

Participants. Thirty-four native speakers of German between the ages of 18 and 35 from Heinrich-Heine-Universität participated in the experiment. They were compensated with either course credit or a payment of $€ 3$.

Design, materials, and procedure. The design and the materials were identical to those of Experiment 2. Experiment 3 differed from Experiment 2 in that each general knowledge question was presented along with a word stem for the predetermined responses. The truth and lie responses for each question were determined by the experimenter. Participants were told that once they saw the on-screen question, they had to complete the word stems with the appropriate truthful or lie response as quickly as possible (e.g., "Which fruit is associated with monkeys?" For the truthful response, "ban__" appeared; for the lie response,

\footnotetext{
${ }^{4}$ As in Experiment 1,2 participants misunderstood the instructions for the truth-check phase and provided the answers that they provided at encoding phase. Thus, these participants' responses to questions for lie condition were excluded from the truth-check analyses.

${ }^{5}$ Gamma correlations were not calculated for 4 participants in truth trials, as these participants always produced the same JOLs for this condition or failed to remember any words from truth trials.
} 
A

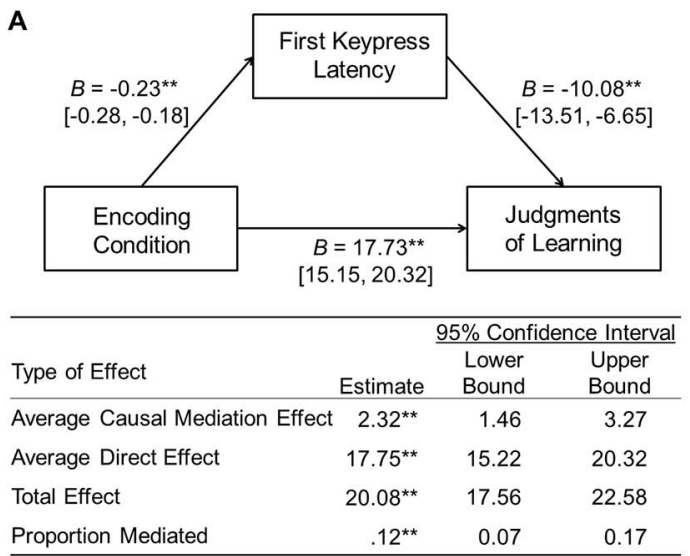

B

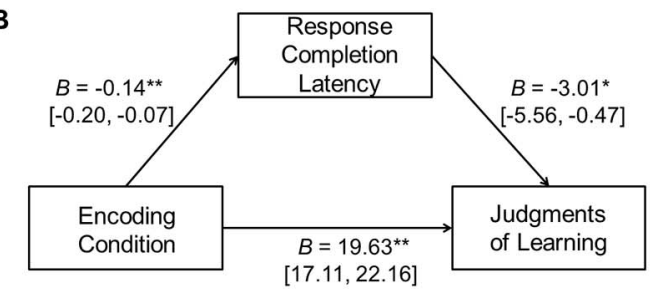

\begin{tabular}{lccc}
\hline & \multicolumn{3}{c}{$95 \%$ Confidence Interval } \\
\cline { 3 - 4 } Type of Effect & Lower & Upper \\
\hline Average Causal Mediation Effect & $0.41^{*}$ & 0.05 & 0.86 \\
Average Direct Effect & $19.63^{* *}$ & 17.19 & 22.11 \\
Total Effect & $20.04^{* *}$ & 17.58 & 22.50 \\
Proportion Mediated & $.02^{*}$ & 0.003 & 0.04 \\
\hline
\end{tabular}

Figure 2. Experiment 2 unstandardized regression coefficients(95\% confidence interval $[\mathrm{CI}]$ ) for the direct effects of encoding condition on latency and for the direct effects of encoding condition and latency on judgments of learning, separately for first keypress latency (Panel A) and response completion latency (Panel B). The complementary tables below each figure show the estimates of the unstandardized regression coefficients and their $95 \%$ CIs for direct effects, indirect (average causal mediation) effects, total effects, and the proportion of mediation for each causal mediation analysis. ${ }^{*} p<.05 .{ }^{* *} p<.01$.

"app__" appeared) and remember their responses for a subsequent memory test. An English version of the experimenter-determined truth and lie responses are presented in Appendix A. As in Experiment 2, each question was presented for a total of $12 \mathrm{~s}$, and the program recorded first keypress latency and response completion latency. Self-paced JOLs followed each trial. The distractor, the testing, and the truth-check phases were identical to those in Experiment 1 and 2.

\section{Results and Discussion}

Response latencies, metamemory, and memory. Table 1 shows the basic descriptive statistics for Experiment 3. Two participants were not able to fulfill the preset criteria of following the procedure for $80 \%$ of the trials and were replaced with 2 participants in the same condition, leaving an effective number of 32 participants. For encoding, participants followed the procedure $99 \%$ of the time for both truth and lie trials. A sign test showed that the procedure compliance was not significantly different across encoding conditions $(p=.727)$.

Trials in which participants did not follow the procedure (1.1\%) were excluded from the latency analyses. At encoding, participants' first keypress was significantly faster for truth trials than for lie trials, $t(31)=5.56, p<.001, d=.98$. Moreover, it took more time to complete the responses for the lies than for the truth, $t(31)=2.61, p=.014, d=0.46$.

Trials in which participants did not follow the procedure or failed to enter their JOLs $(2.34 \%)$ were excluded from the JOL analyses. Two paired-samples $t$ test revealed that participants' JOLs for truth trials were higher than their JOLs for the lie trials, $t(31)=6.32, p<.001, d=1.12$, and their free recall performance was lower for truth trials than for lie trials, $t(31)=3.66, p=.001$, $d=.65$.

The truth-check phase revealed that the correct response rates for truth $(99.43 \%)$ and lie $(96.75 \%)$ condition were quite high. ${ }^{6}$ The sign test revealed that the correct response rate to truth condition was significantly higher than the lie condition by a sign test $(p=.012)$.

Measures of resolution. For Goodman-Kruskal gamma correlations, trials in which participants did not follow the procedure or failed to type in their JOLs were excluded (exclusion rate $=$ $2.34 \%$ ) The mean gamma correlation for truth trials was -.09 $(S D=.58)$ and was not significantly different than 0 in a onesample $t$ test, $t(25)=.80, p=.428, d=.16$. The mean gamma correlation for lie trials was $.17(S D=.41)$ and was significantly different than $0, t(30)=2.32, p=.027, d=.42 .^{7}$ A pairwise comparison of the resolution that the resolution for lie trials was significantly higher than the resolution for truth trials, $t(25)=$ 2.27, $p=.032, d=.45$.

Mediational analyses. Of all trials, $2.34 \%$ were excluded from the multilevel regression analyses. The top portion of Figure 3 shows the unstandardized regression coefficients for direct effects of encoding condition (trial type: lie trials $=0$, truth trials $=$ 1) on latency, encoding condition (trial type), and latency on JOLs, separately, for first keypress (see Panel A) and response completion latency (see Panel B) for Experiment 3.

The complementary tables in the lower portion of Figure 3 show the estimates of the unstandardized regression coefficients for indirect effects, direct effects, total effects, and the proportion mediated for the causal mediational analyses, separately, for first keypress latency (see Panel A) and response completion latency (see Panel B). For first keypress mediational analyses, the direct effect of lie-generation manipulation on JOLs was 16.31 , (95\% CI $[14.30,18.29], p<.001)$. The indirect effect of lie generation

\footnotetext{
${ }^{6}$ Five participants' lie responses were excluded from the truth-check analyses because they misunderstood the instructions at the truth-check phase and provided their responses from the encoding phase.

${ }^{7}$ The correlations for 6 participants in the truth condition and 1 participant in the lie condition were not calculated, as participants always produced the same JOLs in the same condition or they could not remember the any words from one condition.
} 
A

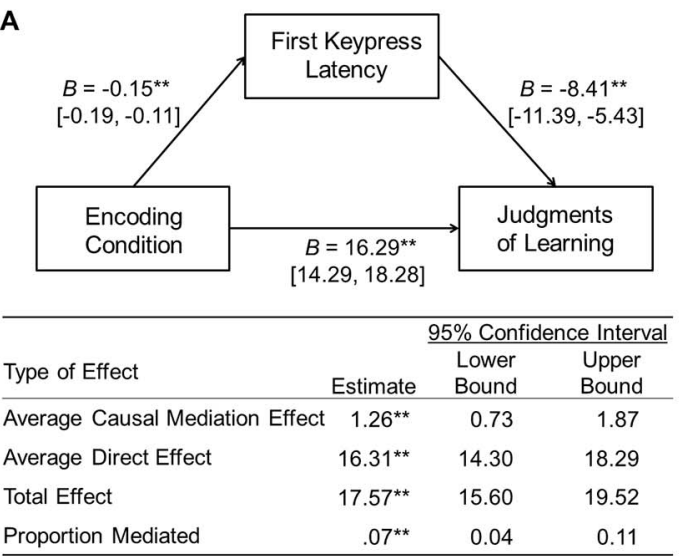

B

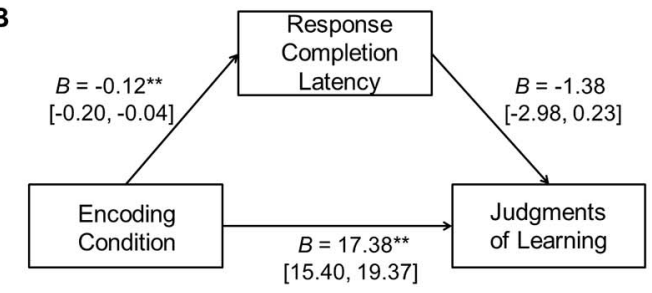

\begin{tabular}{lccc}
\hline & \multicolumn{3}{c}{$95 \%$ Confidence Interval } \\
\cline { 3 - 4 } Type of Effect & Estimate & Bound & Upper \\
Bound \\
\hline Average Causal Mediation Effect & 0.16 & -0.03 & 0.43 \\
Average Direct Effect & $17.38^{\star *}$ & 15.42 & 19.35 \\
Total Effect & $17.54^{\star \star}$ & 15.61 & 19.49 \\
Proportion Mediated & .009 & -.002 & 0.02 \\
\hline
\end{tabular}

Figure 3. Experiment 3 unstandardized regression coefficients (95\% confidence interval $[\mathrm{CI}])$ for the direct effects of encoding condition on latency and for the direct effects of encoding condition and latency on judgments of learning, separately, for first keypress latency (Panel A) and response completion latency (Panel B). The complementary tables below each figure show the estimates of the unstandardized regression coefficients and their 95\% CIs for direct effects, indirect effects (average causal mediation effect), total effects, and the proportion of mediation for each causal mediation analysis. ${ }^{* *} p<.01$.

through first keypress latency was 1.26, (95\% CI [0.73, 1.87], $p<$ $.001)$. The proportion of the total effect of encoding condition on JOLs mediated by first keypress latency was .07, (95\% CI [0.04, $0.11], p<.001)$. For response completion latency, the direct effect of encoding condition on JOLs was 17.38, (95\% CI [15.42, 19.35], $p<.001)$. The indirect effect of encoding through responsecompletion latency was .16, (95\% CI [-0.03, 0.43], $p=.100)$. The proportion of the total effect mediated by response-completion latency was .009 , (95\% CI $[-0.002,0.02], p=.100)$, and not significant.

Over three experiments, generating lies consistently yielded double dissociations between predicted and actual memory performance: Participants predicted that they would recall a higher proportion of their truthful responses, despite their superior actual memory performance for the lies. Moreover, the response latencies for initiating and completing the lie were longer than those for the truth, providing clear and objective evidence of disfluency. First keypress latency always partially mediated the relationship between encoding condition and JOLs, denoting a role for experiencebased processes. Moreover, all these experiments showed that the direct relationship between the encoding manipulation and JOLs was still significant even when the effect of experience-based processes was statistically controlled.

\section{Experiment 4}

In Experiments 1 through 3, participants always had to generate the responses for truth and lie trials on their own, completely or partially, causing them to put in more effort to generate the answers to the lie trials than to the truth trials, resulting in lower JOLs for the lie trials than for the truth trials. In these cases, because generating lies takes longer and requires more effort than telling the truth, as evidenced by the first keypress latency and response completion latency data, participants' JOLs might be a direct consequence of the online difficulties that participants confront while they try to retrieve, generate, and encode their answers for both truth and lie trials. Alternatively, participants might also form a belief that lies are generally remembered less than is the truth, regardless of their own difficulties during the encoding phase; thus, participants might give lower JOLs to lies than to the truth.

The aim of Experiment 4 was to determine whether participants would still produce higher JOLs for truth than for lies, even when experience-based processes were made equally difficult for both encoding conditions. Thus, participants were presented with two choices (one truth, one lie) and were asked to choose (according to the prompt: truth vs. lie) the appropriate responses to general knowledge questions. Even though Experiment 3 required participants to assert less effort for both truth and lie trials, it still required them to exert more effort to generate lie responses than it did to tell the truth because they still needed to retrieve an alternative plausible answer rather than the correct response. However, in Experiment 4 participants were not required to generate either of the responses (i.e., they chose from responses given earlier), thus their memory performance for both truth and lies should be similar. Moreover, their response latency should not change across encoding conditions because they do not have to generate the response. If the lower JOLs for lies found in Experiments 1 through 3 are the consequence of experience-based processes only, then in Experiment 4, where response effort is equalized across truth and lie trials, participants should produce similar JOLs for both. However, if the lower JOLs for lies than for truth are also associated with processes other than experience-based processes, such as theory-based processes, then participants should still give lower JOLs in lie trials, despite the equivalent difficulty involved in choosing the truth or the lie response. For a priori beliefs to be effective in making JOLs, effort differences across encoding conditions are not necessary.

\section{Method}

Participants. Thirty-two native speakers of German between the ages of 18 and 35 from Heinrich-Heine-Universität partici- 
pated in the experiment. They were compensated with either course credit or a payment of $€ 3$.

Design, materials, and procedure. The material consisted of the same questions, and the procedure was similar to previous experiments with a few modifications. Participants were instructed to choose between two responses, one of which was the truth and the other a lie, with respect to the prompt that they were given (truth vs. lie); to remember their chosen responses for a later memory test; and to rate their confidence that they would remember their responses in the subsequent memory test. Participants were given the prompt first and were asked to press $Q$ for the truth trials and $O$ for the lie trials. The corresponding keys for truth and lie prompts were changed for this experiment to automatize responding. Pressing the correct key initiated the display of the question on the screen with one truth and one lie response below the question. If participants chose the response on the right side of the screen, they had to press $S$, and if they chose the answer on the left side, they had to press $K$. Once they pressed the key, the background turned gray, and both responses were left on the screen for a total of $12 \mathrm{~s}$ from the onset of the question on the screen. The encoding condition (truth vs. lie) and the side on which the required response was displayed on the screen (left vs. right) was counterbalanced across participants and presented to an equal number of participants in each condition. Each trial preceded the self-paced JOLs as in previous experiments. Distractor, testing, and truth-check phases were identical to those in Experiments 1 through 3.

\section{Results and Discussion}

Response latencies, metamemory, and memory. Table 1 shows the basic descriptive statistics for Experiment 4. All participants followed the procedure at the preset criteria of at least $80 \%$ of the trials, thus they were all included in the analyses. Participants followed procedure $98 \%$ of the time on truth trials and $96 \%$ of the time on lie trials. A sign test revealed that the compliance to the encoding procedure did not significantly change by encoding condition $(p=.210)$.

As a two-choice test format was used, only latency to respond was obtained. Of all trials, $2.7 \%$ were excluded from the experiment for response latency analyses, as the participants failed to follow procedure for those trials. The mean of the median response latency by encoding condition was submitted to a paired-samples $t$ test and revealed that there was no significant difference in response latency across truth and lie trials, $t(31)=.57, p=.573$, $d=.10$. JOLs differed significantly by encoding condition, $t(31)=3.86, p=.001, d=.68$, with truth trials producing higher JOLs than did lie trials (exclusion rate for JOL analyses $=3.4 \%$ ). Free recall performance did not differ by encoding condition, $t(31)=1.11, p=.275, d=.20$. Both lie and truth trials produced equivalent levels of memory. The truth-check analyses revealed that correct response rates for both truth $(99.25 \%)$ and lie $(99.63 \%)$ conditions were quite high and were not significantly different by a sign test $(p=.687)$.

Measures of resolution. For Goodman-Kruskal gamma correlations, trials in which participants did not follow the procedure or failed to type in their JOLs were excluded (exclusion rate $=$ $3.4 \%$ ) The mean gamma correlation for the truth trials was .43 $(S D=.40)$ and was significantly different than 0 in a one-sample $t$ test, $t(21)=5.07, p<.001, d=1.08$. The mean gamma correlation for lie trials was $.21(S D=.48)$ and was also significantly different than $0, t(25)=2.20, p=.037, d=.43 .^{8} \mathrm{~A}$ paired-samples $t$ test revealed a marginally significant difference across the encoding conditions, $t(21)=2.07, p=.051, d=.44$

The calculation of relative accuracy across Experiments 1 through 4 revealed that they were mostly in the positive direction, but they were quite low for both truth and lie trials in Experiments 1 through 4. Moreover, the pairwise comparisons of relative accuracy across truth and lie trials yielded inconsistent results (i.e., equivalent resolution for Experiment 1, significantly higher resolution for lies than for truth in Experiments 2 and 3, and marginally significant higher resolution for truth than for lies in Experiment 4). A simple pooling of Kruskal-Goodman gamma correlations across four experiments show that both truth trials $(M=.12, S D=$ $.58, n=101)$ and lie trials $(M=.17, S D=.43, n=120)$ are significantly different than 0 in the positive direction $(t[100]=$ $2.05, p=.009, d=.20$, for truth trials; $t[119]=4.36, p<.001$, $d=.40$, for lie trials) and are not significantly different than each other, $t(100)=.60, p=.553, d=.06$. Kruskal-Goodman gamma correlations refer to an item's relative recallibility within a class of items (e.g., truth trials). Thus, if people can identify which items they will recall or forget by assigning higher JOLs for retrieved items and lower JOLs for forgotten items, it yields high positive correlations. In the current case, Kruskal-Goodman gamma correlations are typically made in the right direction, but they are fairly low. This provides additional evidence that the participants are not good judges of their memory performance, and their estimations are equally deficient for truth and lie trials. Finally, as the response latency for truth and lie trials are not significantly different, this experiment did not require mediational analyses.

Experiment 4 used a multiple-choice response manipulation to assess whether JOL differences between truth and lie trials can still be produced when experience-based processes are kept equivalent (i.e., the participants do not have to generate either of the responses) across encoding conditions. Even when the objective difficulty of choosing the response for truth and lie trials was equivalent, as measured by response latency, participants still predicted higher memory performance for truth trials than for lie trials. Thus, even when the role of experience-based processes is ruled out, people still considered a truthful response as more memorable than a plausible lie. Experiments 1 through 3 showed that both experience-based processes made a partial contribution to generating lies through the use of objective latency measures. Experiment 4, in addition, shows that even when the experiencebased processes are similar for lie and truth trials, other factors, possibly theory-based processes, affect judgments and play a prominent role in memory predictions for truth and lies.

Unlike in the previous experiments, the current experiment produced similar levels of free recall performance across encoding conditions. Because the participants do not put extra effort into generating the lies, a null effect for free recall performance is predictable. The post hoc observed power of the current experi-

\footnotetext{
${ }^{8}$ The Kruskal-Goodman gamma correlation was not calculated for 10 participants in the truth condition and 6 participants in the lie condition These participants always produced the same JOLs within the same condition or failed to remember any words from one condition.
} 
ment ( $d=.20, \alpha=.05, N=32$, one-tailed) is .30 . As the power is relatively low, an experiment with a larger sample could have still shown a significant advantage for the free recall of lies compared with the truth. Even then, one can infer that choosing a lie response presented on the screen will be less effective for enhancing memory performance than complete or partial selfgeneration of the lie response.

\section{Experiment 5}

Experiments 1 through 3 showed that RTs for generating lies were longer than were those for telling the truth and partially mediated the relationship between encoding condition and JOLs. This was considered a consequence of experience-based processes. However, Experiment 4 showed reduced JOLs for lies than for the truth, despite no objective fluency differences. Perhaps, this finding can be explained by a priori beliefs about the effects of the lie-generation manipulation. Thus, Experiment 5 applied a straightforward, widely used method (Besken, 2016; Koriat et al., 2004; Kornell et al., 2011; Mueller et al., 2014; Susser et al., 2016) to measure the effects of a priori beliefs on memory predictions. Specifically, participants who have not been exposed to the study materials are asked to read a memory experiment scenario and make predictions about the effect of the lie-generation manipulation. If participants have a priori beliefs about the memorability of truth and lies and in fact believe that truth will be remembered more easily than lies, they should make higher memory predictions for truth trials than for lie trials.

\section{Method}

Participants. A total of 83 Turkish-speaking participants from the community participated in the study voluntarily.

Material, design, and procedure. The data were collected through an online survey that was advertised on various social network pages. Once participants agreed to participate, they read the following description:

Assume that you are participating in an experiment. In the study phase of the experiment, you are presented with 32 general knowledge questions. (For example, the question might be "Which fruit is associated with monkeys?") You are asked to answer half of these questions with the correct response and the rest of the questions with a plausible lie from the same category. (For example, if you are asked to provide the truthful response to the question above, you should say "banana." If you are asked to provide a plausible lie from the same category, you could name another fruit, such as "apple" or "grape"). Each question is displayed on the screen for 12 seconds, and you are required to type your responses by using the keyboard. You are also told that you need to remember your responses for a later memory test.

Assume that you knew the answers to all general knowledge questions, followed the instructions and answered half of the questions with truthful responses and the other half with lie responses.

Now, we would like you to make two predictions about your truthful and lie responses. What percentage of the answers do you think you would remember in a subsequent memory test for your truthful responses? What percentage of answers do you think you would remember in a subsequent memory test for your lie responses? Please make both of your predictions in the sliding scale below. You will need to indicate a separate percentage for truth trials and lie trials.
The program randomly assigned participants to one of the two conditions. In one version, participants read only the experiment scenario without examples (scenario-only condition). In the other version, an example of the questions and plausible truthful and lie responses were also included (scenario-with-example condition). The next page of the questionnaire assured that participants chose the correct explanation for their choice (e.g., "In the previous page, I predicted that I would remember the truthful responses more than the lie responses"). On the subsequent screen, they were asked to indicate the reason for their predictions (e.g., "Why did you think that you would remember more truthful responses than lie responses?"). ${ }^{9}$ Next, participants indicated whether they had participated in any one of the previous experiments about this topic at Bilkent University. On the last page of the questionnaire, they were debriefed about the experiment.

\section{Results and Discussion}

Three participants were excluded from the analyses because they had participated in one of the experiments about lies and memory at Bilkent University. One participant was excluded from the experiment because his or her predictions for truth and lie responses conflicted with the explanation on the confirmation page. This leaves an effective number of 79 participants, with 32 participants randomly assigned by the program to scenario-only condition and 47 participants assigned to the scenario-withexample condition. The mean memory prediction was 75.37 $(S D=24.99)$ for truth responses and $55.34(S D=23.50)$ for lie responses for the scenario-only group. The mean memory prediction was $83.87(S D=20.14)$ for truth responses and $66.28(S D=$ 22.30) for lie responses for the scenario-with-examples group. These means were submitted to a mixed-design analysis of variance with encoding condition prediction (truth vs. lie) as the repeated measures and group (scenario-only vs. scenario-withexamples) as the between-subjects variable. The results showed a main effect for encoding condition, $F(1,77)=42.37, M S_{\text {error }}=$ $318.08, p<.001, \eta_{\mathrm{p}}^{2}=.36$. Participants predicted that they would remember more responses from the truth trials $(M=80.43, S D=$ $22.47)$ than from the lie trials $(M=61.85, S D=23.28)$. There was also a main effect for the experimental group, $F(1,77)=5.17$, $M S_{\text {error }}=695.11, p=.026, \eta_{\mathrm{p}}^{2}=.06$. Participants predicted they would remember a higher percentage of responses if they were assigned to the scenario-with-examples group $(M=75.06, S D=$ 21.22) compared with the scenario-only group $(M=65.36, S D=$ 24.24). The interaction between encoding condition and group was not significant, $F(1,77)=.18, M S_{\text {error }}=318.08, p=.675, \eta_{\mathrm{p}}^{2}=$ .002 .

The current experiment aimed to investigate whether reading an experimental scenario about the lie-generation manipulation produces memory predictions that are comparable to actual experiment participation. Participants made higher memory predictions for truth responses than for lie responses, in line with the results of Experiments 1 through 4, despite the fact that they were not exposed to the experimental paradigm, which shows that the participants might have some beliefs about the lie-generation manipulation, even without participating in the actual experiment. This finding constitutes evidence for the role of theory-based pro-

${ }^{9}$ The responses to this question are not reported for brevity purposes. 
cesses in memory predictions in the current paradigm. Experiments 1 through 3 revealed that experience-based processes partially mediated the relationship between the encoding condition and JOLs. The results of the current experiment suggest that some of the unexplained variance for this effect may be accounted for by the theory-based processes used by the participants.

\section{General Discussion}

Lying has been widely examined in the context of many behavioral measures, such as RTs (Verschuere et al., 2011; Vrij et al., 2008; Walczyk et al., 2003, 2009; Williams et al., 2013), facial (Ekman, O’Sullivan, Friesen, \& Scherer, 1991; Feldman, Jenkins, \& Popoola, 1979; Wojciechowski, Stolarski, \& Matthews, 2014), bodily (Gamer, Bauermann, Stoeter, \& Vossel, 2007; Gödert, Rill, \& Vossel, 2001), vocal (Bogaard, Meijer, Vrij, \& Merckelbach, 2016; Zuckerman, DeFrank, Hall, Larrance, \& Rosenthal, 1979), linguistic (Hauch, Blandón-Gitlin, Masip, \& Sporer, 2015; Newman, Pennebaker, Berry, \& Richards, 2003), paralinguistic (Vrij, Edward, Roberts, \& Bull, 2000; Vrij, Evans, Akehurst, \& Mann, 2004), and textual measures (Lee, Welker, \& Odom, 2009; Zhou, Burgoon, Nunamaker, \& Twitchell, 2004). Most of previous research examined lying in terms of its detection by other people (DePaulo et al., 2003; Hartwig \& Bond, 2011). However, lying may also have important consequences for the liars themselves, specifically in terms of its effects on liars' predicted and actual memory performance. The current set of experiments investigated how lying may impact these two measures and explored the mechanisms underlying these findings. In a set of five experiments, participants were asked to tell the truth to some general knowledge questions and generate plausible incorrect responses to the rest, remember these responses for a subsequent free recall test, and make predictions for their future memory performance on remembering the responses.

First, the main goal of the current research was to systematically test whether a lie-generation manipulation would impact people's free recall performance differently across truth and lie trials. It was hypothesized that generating lies would lead to better free recall performance than would telling the truth, as long as generating lies required more effortful processing at encoding. As expected, Experiments 1 through 3 produced better free recall performance for the lies than for the truth. This is consistent with previous research that investigated the effect of intentional lying on memory (Pickel, 2004; Verschuere, Rosenfeld, Winograd, Labkovsky, \& Wiersema, 2009). From a theoretical perspective, this result fits with the literature because these experiments required participants to generate the responses for both truth and lie trials entirely (Experiments 1 and 2) or partially (Experiment 3 ). Typically, generating lies requires more effort and time than does telling the truth because participants must find the truthful response, suppress it, and find a plausible alternative response (Walczyk et al., 2003, 2014; Williams et al., 2013). Consistent with the literature, more effort in the form of elaboration or self-generation produces higher memory performance, specifically with free recall tests (Hasher \& Zacks, 1979; Hintzman, 2011; McDaniel \& Bugg, 2008; Mulligan \& Lozito, 2004). However, when participants do not have to put more effort into lying, this is not the case. Experiment 4 required participants to choose between the predetermined truth and lie responses rather than generating them, therefore they did not benefit from the mental effort invested in elaborating or generating the responses, and thus this manipulation produced equivalent memory performance across truth and lie trials.

Even though the impact of lying on memory has previously been shown through some research, the more critical aim of the current study was to answer another question: How do people expect their subsequent memory performance to be for truthful responses and self-generated lies at the time of producing the response at encoding? It has been previously shown that fluency affects JOLs and the confidence that one will remember an item in a subsequent memory test, producing higher JOLs for fluent than for disfluent items (Bjork, Dunlosky, \& Kornell, 2013). Considering that lying is associated with longer response latencies, more effortful processing, and increased activity in the brain than does telling the truth, lying may be conceptualized as more disfluent than is telling the truth. Accordingly, it was hypothesized that the more fluent truth trials should lead to higher JOLs than the disfluent lie trials. As hypothesized, all experiments reported here produced higher JOLs for the truth trials than for the lie trials, despite participants' higher free recall performance for the lie responses. From a reallife perspective, participants are not aware that generating lies sometimes enhances their memory performance. Even though participants' free recall performance is generally better for the lies, they believe that they will remember the truth easier in subsequent memory tests. Moreover, analyses pertaining to resolution from Experiments 1 through 4 show that the Goodman-Kruskal gamma correlations are relatively low, but typically in the right direction for both truth and lie trials. This shows that participants are not good judges of their own subsequent memory performance when they have to respond to general knowledge questions, regardless of whether they tell the truth or generate a lie.

From a theoretical perspective, this finding is important in various ways. First, the consistent finding of higher predicted memory for the truth responses than the lie responses across the first four experiments show that generating lies is in fact very similar to other manipulations of fluency, such as retrieval fluency (Benjamin et al., 1998), perceptual fluency (Besken, 2016; Besken \& Mulligan, 2013, 2014; Rhodes \& Castel, 2008, 2009; Yue et al., 2013), and encoding fluency (Begg et al., 1989; Hertzog et al., 2003). When participants run into difficulties at the time of encoding, they produce lower JOLs for the more difficult, disfluent condition than the fluent condition when they perceive, retrieve, or process the items. Lie generation, in this sense, involves similar processes: Participants have to retrieve the correct response, suppress it, find a plausible alternative (Sporer, 2016; Vendemia et al., 2005; Walczyk et al., 2003; Williams et al., 2013), and remember their response for a later memory test, involving several of the processes associated with previous manipulations of processing fluency (Begg et al., 1989; Hertzog et al., 2003) and retrieval fluency (Benjamin et al., 1998). The experiments reported here constitute the first systematic instance of studies in which a liegeneration manipulation has been consistently shown to produce lower memory predictions than does truth telling.

A second important theoretical contribution of the current study is that the experiments reported here produced higher predicted memory paired with the lower actual memory performance for the truth than for the lies, revealing a double dissociation consistently across experiments. In this way, lie generation can be considered as a metacognitive illusion, similar to 
some other metacognitive illusions of fluency, such as illusions of perceptual fluency (Besken \& Mulligan, 2013, 2014; Rhodes \& Castel, 2008) and retrieval fluency (Benjamin et al., 1998). These double dissociations between metamemory and memory across multiple experiments show that actual and predicted memory for the lie-generation manipulation are undergirded by different mechanisms and present evidence that generating lies leads to disparate consequences for these two separate processes. Such double-dissociations also provide us with strong evidence that generating lies may create a metacognitive illusion rather than a simple mismatch between memory and metamemory, unlike single dissociations (Berry et al., 2008; Dunn \& Kirsner, 1988).

A third contribution of the experiments reported here is to propose an avenue along which one can investigate the underlying mechanisms of lying on predicted memory performance. In all experiments reported here, the more disfluent condition of generating lies produced lower JOLs than did the more fluent condition of telling the truth. Generally, this can be considered a consequence of fluency. Over the last decade, a controversy regarding how fluency affects JOLs has revolved around two different types of processes: nonanalytic, experience-based processes versus analytic, theory-based processes (Koriat et al., 2004; Matvey et al., 2001). As explained before, experience-based processes (or nonanalytic basis of JOLs) refer to the online processes that the participant undergoes while perceiving, retrieving, or encoding the items. If an item is more difficult to process by any of these means, then this might decrease JOLs directly because of the experienced lack of fluency for one level of the manipulation at the time of encoding. Various types of latencies, such as lexical decision (Mueller et al., 2014), self-paced study times (Mueller et al., 2014; Undorf \& Erdfelder, 2015), utterance latency (Besken \& Mulligan, 2014), first keypress, and response completion latency (Besken, 2016; Serra \& Dunlosky, 2005) are considered indices of experience-based processes (Dunlosky, Mueller, \& Tauber, 2015). Experiments 1 through 4 reported here made use of response latency measures to assess the contribution of experience-based processes to the lie-generation manipulation. In Experiments 1 through 3, lying produced longer response latencies than did telling the truth in terms of both initiation and completion of the responses. Hence, these experiments show that generating lies is in fact objectively more disfluent than is telling the truth, which is consistent with previous research. If the measures of response latency partially or completely mediate the relationship between the levels of the lie-generation manipulation and JOLs, this can be considered a direct impact of the experience-based processes on JOLs. As shown in Experiments 1 through 3, response latencies, specifically the time that it took participants to start typing their answers, partially mediated the aforementioned relationship, implying a role for experience-based processes.

Theory-based processes (or analytic basis of JOLs), on the other hand, refer to beliefs formed before or during the experiment about the manipulation, without reference to specific episodes. The impact of theory-based processes on JOLs can be implied through various methods. First, if experience-based processes can only account for some of the variation in the relationship between the manipulation and JOLs, the remainder of the relationship could represent the contribution of theory-based processes (Besken, 2016; Besken \& Mulligan, 2013; Mueller et al., 2014, 2016; Undorf \& Erdfelder, 2015). Exper- iments 1 through 3 provide evidence for this, as response latencies could only partially account for the relationship between liegeneration and JOLs. Second, theory-based processes can be implied if JOLs are higher for the fluent truth condition than for the disfluent lie condition, despite the lack of differences in objective measures of fluency (Mueller et al., 2014), or if the experience-based processes fail to mediate the relationship between fluency and JOLs (Mueller et al., 2016; Susser, Jin, \& Mulligan, 2016). Experiment 4 provides more evidence for theory-based processes, as participants produced higher JOLs for truth than for lies, despite the lack of objective response latency differences. Third, participants can be directly asked about their beliefs through questionnaires without being exposed to the experimental materials (Besken, 2016; Koriat et al., 2004; Kornell et al., 2011; Mueller et al., 2014; Susser et al., 2016), make JOLs before they are exposed to the specific episode on an item-by-item basis (Mueller et al., 2014, 2016), or make global estimations about the predicted memory performance before the experiment begins (Frank \& Kuhlmann, 2016). Experiment 5 showed the contribution of a priori beliefs to JOLs through the presentation of a scenario, in which participants had to predict their memory performance without exposure to the experiment, revealing higher memory predictions for truth trials than lie trials. It is important to express that experience-based and theory-based processes do not need to be mutually exclusive, and both might contribute to JOLs to different extents. The implication of the experiments reported here is that both experience- and theory-based processes contribute independently to the JOLs for the lie-generation manipulation; however, the contribution of experience-based processes might be relatively minor (Experiments 1 through 3 ) and not always necessary to induce the effect (Experiments 4 through 5).

The experiments reported here have practical implications in addition to their theoretical contributions. These experiments constitute a basic paradigm through which the impact of intentional lying on memory and metamemory measures can be tested. Foremost, in real-life settings, such as police investigations or job interviews, the suspects or the candidates can be reminded that they will be questioned again later for the same information. If they are in fact less confident about their memory for the lies than for the truth and are constantly reminded to think of their later memory performance, they might refrain from lying more often. In line with Abraham Lincoln's quote "No man has a good enough memory to be a successful liar," people may already have engrained beliefs about the impact of lies on memory. If these beliefs are activated in real-life scenarios, they might reduce the attempts to lie.

One limitation of the current lie-generation paradigm is the operationalization of lying as "the generation of incorrect plausible responses from the same category to general knowledge questions." Clearly, this operationalization may not involve exactly the same processes that are involved in high-stakes lies to episodic incidents or lies for personal, semantic questions. However, there are many examples of experimental paradigms for lie generation that use nonpersonal and semantic questions as well. In some recent experiments, for example, participants lied about the color of the triangles (Williams et al., 2013) or pictures of objects (Vieira \& Lane, 2013), which both required use of generation of impersonal, semantic, and incorrect responses to the questions. Thus, the use of the current paradigm might make the comparison to similar paradigms easier. 
Operationalization of lying as the generation of incorrect plausible responses to general knowledge questions might in some ways be similar to generating lies about one's personal semantic information. In real life, one does not always have to experience an episode in order to lie about it. People frequently lie about semantic information as well. For example, a psychologist on a plane ride might intentionally lie and misrepresent their profession as an accountant to avoid questions and complaints about other passengers' personal lives. In such a case, the person is not necessarily drawing on events from their episodic recollection; instead, they are generating a plausible incorrect response from the same semantic category (i.e., profession). A similar point has been made by other researchers (Depaulo \& Bond, 2012). Clearly, the answers to general knowledge questions comprise part of a person's semantic memory knowledge, and participants learned and practiced the answers of these questions quite often over their lifetime, as also shown with the high percentage of correct answers in truthcheck phase analyses. Thus, the underlying cognitive mechanisms by which general knowledge questions and personal semantic information are produced might be similar (Walczyk et al., 2014). In all of these situations, personal or impersonal, there are two basic mechanisms that do not change: Participants need to remember the actual information (retrieval fluency) and then generate a plausible alternative answer that makes sense within the context (lie-generation fluency). If we can identify and understand the fundamental cognitive processes that guide lying through the use of the basic operationalization of "generating plausible incorrect information," we can draw on cognitive, metacognitive, and emotional processes underlying complex lies in a more controlled manner. Thus, it is important to build on the basic lying paradigms before examining high-stakes, emotion-involved, goal-directed lying paradigms.

It is also important to acknowledge that lying about episodic incidents might be more complicated than is lying about personal, semantic information, it might consist of other underlying mechanisms, and it might produce results that are different than the ones obtained here. For example, when one has to lie in court and goes through cross-examination for more complex lies, it might be more difficult to keep the facts straight, and the metacognitive illusion that this lie-generation paradigm produces between memory and metamemory may be replaced by a main effect that shows that truth is also remembered better than lies. Moreover, the liegeneration manipulation might produce different types of results when tested through recognition or cued recall rather than free recall. Previous research has shown that many manipulations, such as distinctiveness (e.g., Dobbins, Kroll, Yonelinas, \& Liu, 1998), word frequency (e.g., MacLeod, \& Kampe, 1996), and bizarreness (e.g., Riefer \& Rouder, 1992) produce dissociated results when tested through free recall rather than recognition or cued recall. For example, distinctiveness is sensitive to recall, but not to recognition. In a similar vein, when participants lie during encoding, lying might be more distinctive to participants than telling the truth in free recall tests, but these results may not generalize to cued-recall and recognition tests. Therefore, it is important to be cautious about making generalizations about the current results, and future studies should investigate them further.

In conclusion, the three-way relationships among lying, memory, and metamemory is a compelling topic to explore further. The current study shows that a highly controlled lie-generation manip- ulation in a laboratory setting led to a double dissociation between predicted and actual memory: Lie-generation manipulation produced higher memory predictions for the truth, despite the better free recall performance for the lies. This finding is built on a solid understanding of metacognitive and mnemonic processes, and it shows that generating lies can affect these measures in completely different directions. The experiments reported here have many theoretical and applied implications and opens up a novel venue for exploration of the effects of lying on metamemory and memory processes.

There are many research questions that could follow from these findings, from their application in real-life settings to their impact on highly practiced lies in the laboratory. Obviously, the follow-up research on the current paradigm should assess many other questions. For example, does disclosing more information about the type of memory test change metacognitive JOLs? Can this paradigm be used with different types of memory tests such as recognition and cued recall? How are judgments of learning and actual memory performance affected when participants have to lie to the same question more than once? Does a between-subjects design reveal results that are similar to within-subjects designs for recall and memory predictions? Do lower JOLs for the disfluent lie condition be generalized to more personal, high-stakes episodic lies? Clearly, the follow-up experiments will provide a more thorough understanding of the relationships among lying, memory, and metamemory.

\section{References}

Alter, A. L., \& Oppenheimer, D. M. (2009). Uniting the tribes of fluency to form a metacognitive nation. Personality and Social Psychology Review, 13, 219-235. http://dx.doi.org/10.1177/1088868309341564

Bates, D., Maechler, M., Bolker, B., \& Walker, S. (2015). lme4: Linear mixed-effects models using Eigen and S4. Journal of Statistical Software. Advance online publication. http://dx.doi.org/10.18637/jss.v067 .i01

Begg, I., Duft, S., Lalonde, P., Melnick, R., \& Sanvito, J. (1989). Memory predictions are based on ease of processing. Journal of Memory and Language, 28, 610-632. http://dx.doi.org/10.1016/0749-596X(89)90 016-8

Begg, I., Vinski, E., Frankovich, L., \& Holgate, B. (1991). Generating makes words memorable, but so does effective reading. Memory \& Cognition, 19, 487-497. http://dx.doi.org/10.3758/BF03199571

Benjamin, A. S., Bjork, R. A., \& Schwartz, B. L. (1998). The mismeasure of memory: When retrieval fluency is misleading as a metamnemonic index. Journal of Experimental Psychology: General, 127, 55-68. http:// dx.doi.org/10.1037/0096-3445.127.1.55

Berry, C. J., Shanks, D. R., \& Henson, R. N. A. (2008). A single-system account of the relationship between priming, recognition, and fluency. Journal of Experimental Psychology: Learning, Memory, and Cognition, 34, 97-111. http://dx.doi.org/10.1037/0278-7393.34.1.97

Bertsch, S., Pesta, B. J., Wiscott, R., \& McDaniel, M. A. (2007). The generation effect: A meta-analytic review. Memory \& Cognition, 35, 201-210. http://dx.doi.org/10.3758/BF03193441

Besken, M. (2016). Picture-perfect is not perfect for metamemory: Testing the perceptual fluency hypothesis with degraded images. Journal of Experimental Psychology: Learning, Memory, and Cognition, 42, 14171433. http://dx.doi.org/10.1037/xlm0000246

Besken, M., \& Mulligan, N. W. (2013). Easily perceived, easily remembered? Perceptual interference produces a double dissociation between metamemory and memory performance. Memory \& Cognition, 41, 897903. http://dx.doi.org/10.3758/s13421-013-0307-8 
Besken, M., \& Mulligan, N. W. (2014). Perceptual fluency, auditory generation, and metamemory: Analyzing the perceptual fluency hypothesis in the auditory modality. Journal of Experimental Psychology: Learning, Memory, and Cognition, 40, 429-440. http://dx.doi.org/10 $.1037 / \mathrm{a} 0034407$

Bjork, R. A., Dunlosky, J., \& Kornell, N. (2013). Self-regulated learning: Beliefs, techniques, and illusions. Annual Review of Psychology, 64, 417-444. http://dx.doi.org/10.1146/annurev-psych-113011-143823

Bogaard, G., Meijer, E. H., Vrij, A., \& Merckelbach, H. (2016). Strong, but wrong: Lay people's and police officers' beliefs about verbal and nonverbal cues to deception. PLOS ONE, 11, e0156615. http://dx.doi.org/10 .1371/journal.pone.0156615

Bond, C. F., \& Depaulo, B. M. (2008). Individual differences in judging deception: Accuracy and bias. Psychological Bulletin, 134, 477-492. http://dx.doi.org/10.1037/0033-2909.134.4.477

Bond, C. F., Jr., \& DePaulo, B. M. (2006). Accuracy of deception judgments. Personality and Social Psychology Review, 10, 214-234. http:// dx.doi.org/10.1207/s15327957pspr1003_2

Castel, A. D., Rhodes, M. G., \& Friedman, M. C. (2013). Predicting memory benefits in the production effect: The use and misuse of selfgenerated distinctive cues when making judgments of learning. Memory \& Cognition, 41, 28-35. http://dx.doi.org/10.3758/s13421-012-0249-6

Chrobak, Q. M., \& Zaragoza, M. S. (2008). Inventing stories: Forcing witnesses to fabricate entire fictitious events leads to freely reported false memories. Psychonomic Bulletin \& Review, 15, 1190-1195. http:// dx.doi.org/10.3758/PBR.15.6.1190

Chrobak, Q. M., \& Zaragoza, M. S. (2013). When forced fabrications become truth: Causal explanations and false memory development. Journal of Experimental Psychology: General, 142, 827-844. http://dx .doi.org/10.1037/a0030093

Colwell, K., Hiscock-Anisman, C., Corbett, L., Memon, A., Hauselt, W. J., \& Bonilla, Y. (2011). Change in suspect's memory as a result of deception. The American Journal of Forensic Psychology, 29, 1-9.

Depaulo, B. M., \& Bond, C. F., Jr. (2012). Bigger, broader ways to think about deceit. Journal of Applied Research in Memory \& Cognition, 1, 120-121. http://dx.doi.org/10.1016/j.jarmac.2012.04.010

DePaulo, B. M., Lindsay, J. J., Malone, B. E., Muhlenbruck, L., Charlton, K., \& Cooper, H. (2003). Cues to deception. Psychological Bulletin, 129, 74-118. http://dx.doi.org/10.1037/0033-2909.129.1.74

Dobbins, I. G., Kroll, N. E., Yonelinas, A. P., \& Liu, Q. (1998). Distinctiveness in recognition and free recall: The role of recollection in the rejection of the familiar. Journal of Memory and Language, 38, 381400. http://dx.doi.org/10.1006/jmla.1997.2554

Dunlosky, J., Mueller, M. K., \& Tauber, S. K. (2015). The contribution of subjective fluency and theories of memory to people's judgments of memory. In D. S. Lindsay, C. M. Kelley, A. P. Yonelinas, \& H. L. Roediger III, (Eds.), Remembering: attributions, processes, and control in human memory: Papers in Honour of Larry L. Jacoby (pp. 46-64). New York, NY: Psychology Press.

Dunn, J. C., \& Kirsner, K. (1988). Discovering functionally independent mental processes: The principle of reversed association. Psychological Review, 95, 91-101. http://dx.doi.org/10.1037/0033-295X.95.1.91

Ekman, P., O'Sullivan, M., Friesen, W. V., \& Scherer, K. R. (1991). Invited article: Face, voice, and body in detecting deceit. Journal of Nonverbal Behavior, 15, 125-135. http://dx.doi.org/10.1007/BF00 998267

Farah, M. J., Hutchinson, J. B., Phelps, E. A., \& Wagner, A. D. (2014). Functional MRI-based lie detection: Scientific and societal challenges. Nature Reviews Neuroscience, 15, 123-131. http://dx.doi.org/10.1038/ nrn3665

Faul, F., Erdfelder, E., Buchner, A., \& Lang, A.-G. (2009). Statistical power analyses using $G^{*}$ Power 3.1: Tests for correlation and regression analyses. Behavior Research Methods, 41, 1149-1160. http://dx.doi.org/ 10.3758/BRM.41.4.1149
Feldman, R. S., Jenkins, L., \& Popoola, O. (1979). Detection of deception in adults and children via facial expressions. Child Development, 50, 350-355. http://dx.doi.org/10.2307/1129409

Frank, D. J., \& Kuhlmann, B. G. (2016). More than just beliefs: Experience and beliefs jointly contribute to volume effects on metacognitive judgments. Journal of Experimental Psychology: Learning, Memory, and Cognition. Advance online publication. http://dx.doi.org/10.1037/ xlm0000332

Gamer, M., Bauermann, T., Stoeter, P., \& Vossel, G. (2007). Covariations among fMRI, skin conductance, and behavioral data during processing of concealed information. Human Brain Mapping, 28, 1287-1301. http://dx.doi.org/10.1002/hbm.20343

Gneezy, U. (2005). Deception: The role of consequences. The American Economic Review, 95, 384-394. http://dx.doi.org/10.1257/0002828 053828662

Gödert, H. W., Rill, H. G., \& Vossel, G. (2001). Psychophysiological differentiation of deception: The effects of electrodermal lability and mode of responding on skin conductance and heart rate. International Journal of Psychophysiology, 40, 61-75. http://dx.doi.org/10.1016/ S0167-8760(00)00149-5

Gombos, V. A. (2006). The cognition of deception: The role of executive processes in producing lies. Genetic, Social, and General Psychology Monographs, 132, 197-214. http://dx.doi.org/10.3200/MONO.132.3 $.197-214$

Hartwig, M., \& Bond, C. F., Jr. (2011). Why do lie-catchers fail? A lens model meta-analysis of human lie judgments. Psychological Bulletin, 137, 643-659. http://dx.doi.org/10.1037/a0023589

Hasher, L., \& Zacks, R. T. (1979). Automatic and effortful processes in memory. Journal of Experimental Psychology: General, 108, 356-388. http://dx.doi.org/10.1037/0096-3445.108.3.356

Hauch, V., Blandón-Gitlin, I., Masip, J., \& Sporer, S. L. (2015). Are computers effective lie detectors? A meta-analysis of linguistic cues to deception. Personality and Social Psychology Review, 19, 307-342. http://dx.doi.org/10.1177/1088868314556539

Hauch, V., Sporer, S. L., Michael, S. W., \& Meissner, C. A. (2016). Does training improve the detection of deception? A meta-analysis. Communication Research, 43, 283-343. http://dx.doi.org/10.1177/009365021 4534974

Hertzog, C., Dunlosky, J., Robinson, A. E., \& Kidder, D. P. (2003). Encoding fluency is a cue used for judgments about learning. Journal of Experimental Psychology: Learning, Memory, and Cognition, 29, 2234. http://dx.doi.org/10.1037/0278-7393.29.1.22

Hintzman, D. L. (2011). Research strategy in the study of memory: Fads, fallacies, and the search for the "coordinates of truth." Perspectives on Psychological Science, 6, 253-271. http://dx.doi.org/10.1177/ 1745691611406924

Hu, C., Huang, K., Hu, X., Liu, Y., Yuan, F., Wang, Q., \& Fu, G. (2015). Measuring the cognitive resources consumed per second for real-time lie-production and recollection: A dual-tasking paradigm. Frontiers in Psychology, 6, 596. http://dx.doi.org/10.3389/fpsyg.2015.00596

Imai, K., Keele, L., \& Tingley, D. (2010). A general approach to causal mediation analysis. Psychological Methods, 15, 309-334. http://dx.doi .org/10.1037/a0020761

Kelley, C. M., \& Lindsay, D. S. (1993). Remembering mistaken for knowing: Ease of retrieval as a basis for confidence in answers to general knowledge questions. Journal of Memory and Language, 32, 1-24. http://dx.doi.org/10.1006/jmla.1993.1001

Koriat, A., Bjork, R. A., Sheffer, L., \& Bar, S. K. (2004). Predicting one's own forgetting: The role of experience-based and theory-based processes. Journal of Experimental Psychology: General, 133, 643-656. http://dx.doi.org/10.1037/0096-3445.133.4.643

Koriat, A., \& Ma'ayan, H. (2005). The effects of encoding fluency and retrieval fluency on judgments of learning. Journal of Memory and Language, 52, 478-492. http://dx.doi.org/10.1016/j.jml.2005.01.001 
Kornell, N., Rhodes, M. G., Castel, A. D., \& Tauber, S. K. (2011). The ease-of-processing heuristic and the stability bias: Dissociating memory, memory beliefs, and memory judgments. Psychological Science, 22, 787-794. http://dx.doi.org/10.1177/0956797611407929

Lane, S. M., \& Zaragoza, M. S. (2007). A little elaboration goes a long way: The role of generation in eyewitness suggestibility. Memory \& Cognition, 35, 1255-1266. http://dx.doi.org/10.3758/BF03193599

Langleben, D. D., Schroeder, L., Maldjian, J. A., Gur, R. C., McDonald, S., Ragland, J. D., . . Childress, A. R. (2002). Brain activity during simulated deception: An event-related functional magnetic resonance study. NeuroImage, 15, 727-732. http://dx.doi.org/10.1006/nimg.2001.1003

Lee, C. C., Welker, R. B., \& Odom, M. D. (2009). Features of computermediated, text-based messages that support automatable, linguisticsbased indicators for deception detection. Journal of Information Systems, 23, 5-24. http://dx.doi.org/10.2308/jis.2009.23.1.24

MacLeod, C. M., \& Kampe, K. E. (1996). Word frequency effects on recall, recognition, and word fragment completion tests. Journal of Experimental Psychology: Learning, Memory, and Cognition, 22, 132142. http://dx.doi.org/10.1037/0278-7393.22.1.132

Matvey, G., Dunlosky, J., \& Guttentag, R. (2001). Fluency of retrieval at study affects judgments of learning (JOLs): An analytic or nonanalytic basis for JOLs? Memory \& Cognition, 29, 222-233. http://dx.doi.org/ 10.3758/BF03194916

McDaniel, M. A., \& Bugg, J. M. (2008). Instability in memory phenomena: A common puzzle and a unifying explanation. Psychonomic Bulletin \& Review, 15, 237-255. http://dx.doi.org/10.3758/PBR.15.2.237

Mohamed, F. B., Faro, S. H., Gordon, N. J., Platek, S. M., Ahmad, H., \& Williams, J. M. (2006). Brain mapping of deception and truth telling about an ecologically valid situation: Functional MR imaging and polygraph investigation-Initial experience. Radiology, 238, 679-688. http://dx.doi.org/10.1148/radiol.2382050237

Mueller, M. L., Dunlosky, J., \& Tauber, S. K. (2016). The effect of identical word pairs on people's metamemory judgments: What are the contributions of processing fluency and beliefs about memory? Quarterly Journal of Experimental Psychology: Human Experimental Psychology, 69, 781-799. http://dx.doi.org/10.1080/17470218.2015 .1058404

Mueller, M. L., Dunlosky, J., Tauber, S. K., \& Rhodes, M. G. (2014). The font-size effect on judgments of learning: Does it exemplify fluency effects or reflect people's beliefs about memory? Journal of Memory and Language, 70, 1-12. http://dx.doi.org/10.1016/j.jml.2013.09.007

Mulligan, N. W., \& Lozito, J. P. (2004). Self-generation and memory. Psychology of Learning and Motivation, 45, 175-214. http://dx.doi.org/ 10.1016/S0079-7421(03)45005-6

Newman, M. L., Pennebaker, J. W., Berry, D. S., \& Richards, J. M. (2003). Lying words: Predicting deception from linguistic styles. Personality and Social Psychology Bulletin, 29, 665-675. http://dx.doi.org/10.1177/ 0146167203029005010

Oppenheimer, D. M. (2008). The secret life of fluency. Trends in Cognitive Sciences, 12, 237-241. http://dx.doi.org/10.1016/j.tics.2008.02.014

Otgaar, H., Howe, M. L., Memon, A., \& Wang, J. (2014). The development of differential mnemonic effects of false denials and forced confabulations. Behavioral Sciences \& the Law, 32, 718-731. http://dx.doi.org/ $10.1002 / \mathrm{bsl} .2148$

Pickel, K. L. (2004). When a lie becomes the truth: The effects of self-generated misinformation on eyewitness memory. Memory, 12, 14-26. http://dx.doi.org/10.1080/09658210244000072

Polage, D. C. (2004). Fabrication deflation? The mixed effects of lying on memory. Applied Cognitive Psychology, 18, 455-465. http://dx.doi.org/ 10.1002/acp. 995

Polage, D. C. (2012). Fabrication inflation increases as source monitoring ability decreases. Acta Psychologica, 139, 335-342. http://dx.doi.org/10 $.1016 /$ j.actpsy.2011.12.007
R Core Team. (2013). R: A language and environment for statistical computing [Computer software]. Vienna, Austria: R Foundation for Statistical Computing. Retrieved from http://www.R-project.org/

Rhodes, M. G. (2016). Judgments of learning: Methods, data, and theory. In J. Dunlosky \& S. K. Tauber (Eds.), The Oxford handbook of metamemory (pp. 65-80). New York, NY: Oxford University Press.

Rhodes, M. G., \& Castel, A. D. (2008). Memory predictions are influenced by perceptual information: Evidence for metacognitive illusions. Journal of Experimental Psychology: General, 137, 615-625. http://dx.doi .org/10.1037/a0013684

Rhodes, M. G., \& Castel, A. D. (2009). Metacognitive illusions for auditory information: Effects on monitoring and control. Psychonomic Bulletin \& Review, 16, 550-554. http://dx.doi.org/10.3758/PBR.16.3.550

Riefer, D. M., \& Rouder, J. N. (1992). A multinomial modeling analysis of the mnemonic benefits of bizarre imagery. Memory \& Cognition, 20, 601-611. http://dx.doi.org/10.3758/BF03202710

Serota, K. B., Levine, T. R., \& Boster, F. J. (2010). The prevalance of lying in America: Three studies of self-reported lies. Human Communication Research, 36, 2-25. http://dx.doi.org/10.1111/j.1468-2958.2009.01366.x

Serra, M. J., \& Dunlosky, J. (2005). Does retrieval fluency contribute to the underconfidence-with-practice effect? Journal of Experimental Psychology: Learning, Memory, and Cognition, 31, 1258-1266. http://dx.doi .org/10.1037/0278-7393.31.6.1258

Slamecka, N. J., \& Graf, P. (1978). The generation effect: Delineation of a phenomenon. Journal of Experimental Psychology: Human Learning and Memory, 4, 592-604. http://dx.doi.org/10.1037/0278-7393.4.6.592

Sporer, S. L. (2016). Deception and Cognitive Load: Expanding Our Horizon with a Working Memory Model. Frontiers in Psychology, 7, 420. http://dx.doi.org/10.3389/fpsyg.2016.00420

Susser, J. A., Jin, A., \& Mulligan, N. W. (2016). Identity priming consistently affects perceptual fluency but only affects metamemory when primes are obvious. Journal of Experimental Psychology: Learning, Memory, and Cognition, 42, 657-662. http://dx.doi.org/10.1037/xlm0000189

Thiede, K. W., \& Dunlosky, J. (1999). Toward a general model of selfregulated study: An analysis of selection of items for study and selfpaced study time. Journal of Experimental Psychology: Learning, Memory, and Cognition, 25, 1024-1037. http://dx.doi.org/10.1037/02787393.25.4.1024

Tingley, D., Yamamoto, T., Hirose, K., Keele, L., \& Imai, K. (2014). Mediation: R package for causal mediation analysis. Journal of Statistical Software, 59, 1-38. http://dx.doi.org/10.18637/jss.v059.i05

Undorf, M., \& Erdfelder, E. (2015). The relatedness effect on judgments of learning: A closer look at the contribution of processing fluency. Memory \& Cognition, 43, 647-658. http://dx.doi.org/10.3758/s13421-014$0479-x$

Undorf, M., Zimdahl, M. F., \& Bernstein, D. M. (2017). Perceptual fluency contributes to effects of stimulus size on judgments of learning. Journal of Memory and Language, 92, 293-304. http://dx.doi.org/10.1016/j.jml .2016 .07 .003

Van Overschelde, J. P., Rawson, K. A., \& Dunlosky, J. (2004). Category norms: An updated and expanded version of the norms. Journal of Memory and Language, 50, 289-335. http://dx.doi.org/10.1016/j.jml .2003 .10 .003

Vendemia, J. M., Buzan, R. F., \& Simon-Dack, S. L. (2005). Reaction time of motor responses in two-stimulus paradigms involving deception and congruity with varying levels of difficulty. Behavioural Neurology, 16, 25-36. http://dx.doi.org/10.1155/2005/804026

Verschuere, B., Rosenfeld, J. P., Winograd, M. R., Labkovsky, E., \& Wiersema, R. (2009). The role of deception in P300 memory detection. Legal and Criminological Psychology, 14, 253-262. http://dx.doi.org/ 10.1348/135532508X384184

Verschuere, B., Spruyt, A., Meijer, E. H., \& Otgaar, H. (2011). The ease of lying. Consciousness and Cognition, 20, 908-911. http://dx.doi.org/ 10.1016/j.concog.2010.10.023 
Vieira, K. M., \& Lane, S. M. (2013). How you lie affects what you remember. Journal of Applied Research in Memory \& Cognition, 2, 173-178. http://dx.doi.org/10.1016/j.jarmac.2013.05.005

Vrij, A., Edward, K., Roberts, K. P., \& Bull, R. (2000). Detecting deceit via analysis of verbal and nonverbal behavior. Journal of Nonverbal Behavior, 24, 239-263. http://dx.doi.org/10.1023/A:1006610329284

Vrij, A., Evans, H., Akehurst, L., \& Mann, S. (2004). Rapid judgements in assessing verbal and nonverbal cues: Their potential for deception researchers and lie detection. Applied Cognitive Psychology, 18, 283-296. http://dx.doi.org/10.1002/acp.964

Vrij, A., Fisher, R., Mann, S., \& Leal, S. (2006). Detecting deception by manipulating cognitive load. Trends in Cognitive Sciences, 10, 141-142. http://dx.doi.org/10.1016/j.tics.2006.02.003

Vrij, A., Mann, S. A., Fisher, R. P., Leal, S., Milne, R., \& Bull, R. (2008). Increasing cognitive load to facilitate lie detection: The benefit of recalling an event in reverse order. Law and Human Behavior, 32, 253-265. http://dx.doi.org/10.1007/s10979-007-9103-y

Walczyk, J. J., Harris, L. L., Duck, T. K., \& Mulay, D. (2014). A social-cognitive framework for understanding serious lies: Activationdecision-construction-action theory. New Ideas in Psychology, 34, 22 36. http://dx.doi.org/10.1016/j.newideapsych.2014.03.001

Walczyk, J. J., Mahoney, K. T., Doverspike, D., \& Griffith-Ross, D. A. (2009). Cognitive lie detection: Response time and consistency of answers as cues to deception. Journal of Business and Psychology, 24, 33-49. http://dx.doi.org/10.1007/s10869-009-9090-8

Walczyk, J. J., Roper, K. S., Seemann, E., \& Humphrey, A. M. (2003). Cognitive mechanisms underlying lying to questions: Response time as a cue to deception. Applied Cognitive Psychology, 17, 755-774. http:// dx.doi.org/10.1002/acp.914

Williams, E. J., Bott, L. A., Patrick, J., \& Lewis, M. B. (2013). Telling lies: The irrepressible truth? PLOS ONE, 8, e60713. http://dx.doi.org/10 .1371/journal.pone.0060713
Winkielman, P., Schwarz, N., \& Belli, R. F. (1998). The role of ease of retrieval and attribution in memory judgments: Judging your memory as worse despite recalling more events. Psychological Science, 9, 124-126. http://dx.doi.org/10.1111/1467-9280.00022

Wojciechowski, J., Stolarski, M., \& Matthews, G. (2014). Emotional intelligence and mismatching expressive and verbal messages: A contribution to detection of deception. PLoS ONE, 9, e92570. http://dx.doi .org/10.1371/journal.pone.0092570

Yue, C. L., Castel, A. D., \& Bjork, R. A. (2013). When disfluency is-And is not-A desirable difficulty: The influence of typeface clarity on metacognitive judgments and memory. Memory \& Cognition, 41, 229 241. http://dx.doi.org/10.3758/s13421-012-0255-8

Zaragoza, M. S., Mitchell, K. J., Payment, K., \& Drivdahl, S. (2011). False memories for suggestions: The impact of conceptual elaboration. Journal of Memory and Language, 64, 18-31. http://dx.doi.org/10.1016/j.jml.2010.09 .004

Zaragoza, M. S., Payment, K. E., Ackil, J. K., Drivdahl, S. B., \& Beck, M. (2001). Interviewing witnesses: Forced confabulation and confirmatory feedback increase false memories. Psychological Science, 12, 473-477. http://dx.doi.org/10.1111/1467-9280.00388

Zhou, L., Burgoon, J. K., Nunamaker, J. F., \& Twitchell, D. (2004). Automating linguistics-based cues for detecting deception in text-based asynchronous computer-mediated communications. Group Decision and Negotiation, 13, 81-106. http://dx.doi.org/10.1023/B:GRUP.0000011944 $.62889 .6 \mathrm{f}$

Zuckerman, M., DeFrank, R. S., Hall, J. A., Larrance, D. T., \& Rosenthal, R. (1979). Facial and vocal cues of deception and honesty. Journal of Experimental Social Psychology, 15, 378-396. http://dx.doi.org/10 .1016/0022-1031(79)90045-3

Zuckerman, M., DePaulo, B. M., \& Rosenthal, R. (1981). Verbal and nonverbal communication of deception. Advances in Experimental Social Psychology, 14, 1-59. http://dx.doi.org/10.1016/S0065-2601(08)60369-X

\section{Appendix A}

\section{General Knowledge Questions Used in Experiments 1 Through 4}

\begin{tabular}{|c|c|c|c|c|}
\hline Category & Question in german & Question in english & $\begin{array}{l}\text { Correct answer } \\
\quad \text { (truth) }\end{array}$ & $\begin{array}{l}\text { Incorrect answer } \\
\text { (lie) }\end{array}$ \\
\hline Alcoholic beverage & $\begin{array}{l}\text { Welches alkoholische Getränk wird } \\
\text { aus Weintrauben hergestellt? }\end{array}$ & $\begin{array}{l}\text { Which alcoholic drink is made from } \\
\text { grapes? }\end{array}$ & wine & beer \\
\hline Animal & $\begin{array}{l}\text { Welches Tier hat schwarz-weiße } \\
\text { Streifen? }\end{array}$ & Which animal has black and white stripes? & zebra & giraffe \\
\hline City & $\begin{array}{l}\text { Wie heißt die Hauptstadt von } \\
\text { Deutschland? }\end{array}$ & What is the capital of Germany? & Berlin & Dusseldorf \\
\hline Color & Welche Farbe haben Baumstämme? & What color are tree trunks? & brown & blue \\
\hline Communication device & $\begin{array}{l}\text { Welches Gerät verwenden wir, um } \\
\text { andere Personen anzurufen und } \\
\text { mit ihnen zu sprechen, ohne dass } \\
\text { wir sie sehen können? }\end{array}$ & $\begin{array}{l}\text { Which device do we use in order to call } \\
\text { other people even though we are not } \\
\text { able to see them? }\end{array}$ & telephone & computer \\
\hline Country & $\begin{array}{l}\text { In welchem Land steht der } \\
\text { Eiffelturm? }\end{array}$ & In which country is the Eiffel Tower? & France & England \\
\hline Flower & $\begin{array}{l}\text { Welche Blume verschenkt man } \\
\text { typischerweise am Valentinstag? }\end{array}$ & $\begin{array}{l}\text { Which flower is typically given on } \\
\text { Valentine's Day? }\end{array}$ & rose & tulips \\
\hline Fruit & $\begin{array}{l}\text { Welche Frucht verbindet man mit } \\
\text { Affen? }\end{array}$ & Which fruit is associated with monkeys? & banana & apple \\
\hline
\end{tabular}


Appendix A (continued)

\begin{tabular}{|c|c|c|c|c|}
\hline Category & Question in german & Question in english & $\begin{array}{l}\text { Correct answer } \\
\text { (truth) }\end{array}$ & $\begin{array}{l}\text { Incorrect answer } \\
\text { (lie) }\end{array}$ \\
\hline Furniture & $\begin{array}{l}\text { Welches Möbelstück benutzt man } \\
\text { zum Schlafen? }\end{array}$ & $\begin{array}{l}\text { Which piece of furniture is used for } \\
\text { sleeping? }\end{array}$ & bed & table \\
\hline Gas & $\begin{array}{l}\text { Wie heißt das in der Luft } \\
\text { befindliche überlebenswichtige } \\
\text { Gas, das wir einamten? }\end{array}$ & $\begin{array}{l}\text { What is the name of gas that we inhale, } \\
\text { essential for our survival? }\end{array}$ & oxygen & carbondioxide \\
\hline Jewelry & $\begin{array}{l}\text { Welchen Schmuck trägt man an } \\
\text { den Fingern? }\end{array}$ & $\begin{array}{l}\text { What type of jewelry do you wear on your } \\
\text { fingers? }\end{array}$ & ring & chain \\
\hline Kitchen utensil & $\begin{array}{l}\text { Welches Küchengerät wird zum } \\
\text { Schneiden verwendet? }\end{array}$ & $\begin{array}{l}\text { Which kitchen utensil do we use to cut } \\
\text { food? }\end{array}$ & knife & fork \\
\hline Land formation & $\begin{array}{l}\text { Welche Landschaftsformationen } \\
\text { sind der Himalaya und die } \\
\text { Alpen? }\end{array}$ & $\begin{array}{l}\text { What type of land formation are the } \\
\text { Himalayas and the Alps? }\end{array}$ & mountain & island \\
\hline Language & $\begin{array}{l}\text { Was ist die Landessprache in } \\
\text { Amerika? }\end{array}$ & What is the national language of USA? & English & German \\
\hline Length unit & $\begin{array}{l}\text { Welche Maßeinheit entspricht } 100 \\
\text { Zentimetern? }\end{array}$ & Which unit is equal to 100 centimeters? & meter & millimeter \\
\hline Money currency & $\begin{array}{l}\text { Wie heißt die meistgenutzte } \\
\text { Währung der EU? }\end{array}$ & $\begin{array}{l}\text { What is the most commonly used currency } \\
\text { of European Union? }\end{array}$ & Euro & Dollar \\
\hline Planet & Wie heißt unser Planet? & What is the name of our planet? & Earth & Mars \\
\hline Precious stone & $\begin{array}{l}\text { Welcher besonders wertvolle Stein, } \\
\text { dessen Wert in Karat gemessen } \\
\text { wird, wird häufig für } \\
\text { Heiratsanträge verwendet? }\end{array}$ & $\begin{array}{l}\text { What is the name of the stone that is often } \\
\text { used for marriage proposals and } \\
\text { measured in carats? }\end{array}$ & diamond & ruby \\
\hline Prime minister & $\begin{array}{l}\text { Wie heißt der/ die aktuelle } \\
\text { Bundeskanzler/ in? }\end{array}$ & $\begin{array}{l}\text { What is the name of the current } \\
\text { Chancellor of Germany? }\end{array}$ & Merkel & Schroeder \\
\hline Profession & $\begin{array}{l}\text { Wer verteidigt Angeklagte vor } \\
\text { Gericht? }\end{array}$ & Who defends the accused people in court? & lawyer & judge \\
\hline Relative & $\begin{array}{l}\text { Der Bruder deiner Mutter ist dein } \\
\quad \ldots \text { ? }\end{array}$ & $\begin{array}{l}\text { What is your mother's brother is to you as } \\
\text { a relative? }\end{array}$ & uncle & nephew \\
\hline Religion & $\begin{array}{l}\text { In welcher Religion spielt Jesus } \\
\text { eine zentrale Rolle? }\end{array}$ & $\begin{array}{l}\text { In which religion does Jesus play a central } \\
\text { role? }\end{array}$ & Christianity & Buddhism \\
\hline Science & $\begin{array}{l}\text { Welche Wissenschaft beschäftigt } \\
\text { sich mit Materie, Kraft, Energie } \\
\text { und Gravitation? }\end{array}$ & $\begin{array}{l}\text { What science deals with matter, force, } \\
\text { energy and gravity? }\end{array}$ & physics & biology \\
\hline Sensory organ & $\begin{array}{l}\text { Mit welchem Sinnesorgan sehen } \\
\text { wir? }\end{array}$ & Which sensory organ is used for vision? & eye & ear \\
\hline Spice & $\begin{array}{l}\text { Welches Gewürz wird aus } \\
\text { Meerwasser gewonnen? }\end{array}$ & Which spice is obtained from seawater? & salt & pepper \\
\hline Sports equipment & $\begin{array}{l}\text { Mit welchem Sportgerät spielt man } \\
\text { Tennis? }\end{array}$ & $\begin{array}{l}\text { Which sports equipment is used for } \\
\text { playing tennis? }\end{array}$ & racket & football \\
\hline Time unit & $\begin{array}{l}\text { Welche Zeiteinheit besteht aus } 60 \\
\text { Sekunden? }\end{array}$ & What time unit is equal to 60 seconds? & minute & hour \\
\hline Tool & $\begin{array}{l}\text { Mit welchem Werkzeug schlägt } \\
\text { man Nägel in die Wand? }\end{array}$ & $\begin{array}{l}\text { Which tool do you use in order to pound } \\
\text { nails into the wall? }\end{array}$ & hammer & pliers \\
\hline Transportation vehicle & $\begin{array}{l}\text { Welches fliegende Transportmittel } \\
\text { befördert Personen? }\end{array}$ & $\begin{array}{l}\text { What type of vehicle is used to transport } \\
\text { people by air? }\end{array}$ & airplane & car \\
\hline Type of institution & Welche Institution verwaltet Geld? & Which institution manages money? & bank & school \\
\hline Type of music & $\begin{array}{l}\text { Welche Art von Musik } \\
\text { komponierten Bach, Mozart und } \\
\text { Beethoven? }\end{array}$ & $\begin{array}{l}\text { What kind of music did Bach, Mozart and } \\
\text { Beethoven compose? }\end{array}$ & classical music & rock \\
\hline Vegetable & $\begin{array}{l}\text { Welches orangene Gemüse } \\
\text { verbindet man mit Hasen? }\end{array}$ & $\begin{array}{l}\text { What is the name of orange vegetable, } \\
\text { most commonly associated with rabbits? }\end{array}$ & carrot & paprika \\
\hline
\end{tabular}

Note. Correct answer (truthful response) and incorrect answer (lie response) columns indicate the words from which word stems were created for Experiment 3 and multiple choice answers for Experiment 4. 


\section{Appendix B}

\section{Response Coding Schemes for Encoding and Recall}

\section{Scheme for Encoding}

Following the procedure consisted of providing an appropriate answer that was in line with the requirements. Participants were considered to have not followed the procedure if

they typed in a truthful response during a lie trial;

they responded with a lie response during a truth trial;

they skipped the question without typing a response;

they wrote $X X$, indicating that they did not know the correct response;

they started typing a response, but were not able to complete their response beyond three letters; or

they responded with a lie response in a lie trial, but the response was from a completely irrelevant category (e.g. television for city category).

Participants were considered to have followed the procedure if they provided a response that was not from the category that they had to respond with, but the response made sense in context (e.g. "orange" for vegetable, "Paris" for country);

they responded with an incorrect answer in a truth trial, but they thought that this was the correct answer (as indicated in the truth-check phase); or

they responded with a correct answer in a lie trial, but they thought that this was the incorrect answer (as indicated in the truth-check phase).
Some participants failed to follow the procedure at truth-check phase. Instead of answering all questions correctly, they wrote their responses from the first phase again. For these participants, it was assumed that they knew the correct answers to all questions and were scored accordingly. Their scores were excluded from the truth-check phase analyses.

\section{Scheme for Unconditional and Conditional Recall}

All the items that were typed in during the encoding phase and recalled at the free recall test were considered recalled. All the items that were recalled were tallied up separately for truth and lie trials and divided by 16 (the total number of trials for each encoding condition) to obtain the unconditional correct proportion for truth and lie trials.

The correct proportion recalled conditionalized on compliance to procedure included only the recalled items for which the procedure was followed correctly. The number of these items for both truth and lie trials were tallied up separately and divided by the total number of respective trials in which the procedure was followed. For example, if the participant recalled six items out of all truth trials, but she has failed to follow procedure for one of these truth trials, then her total conditionalized score of $5(6-1=$ 5) was divided by the number of truth trials in which the participant followed the procedure $(16-1=15)$. For this particular example, the participant's unconditional proportion correct for truth trials is $6 / 16=.38$, and her proportion correct conditionalized on compliance to procedure is $5 / 15=.33$.

Received December 22, 2016

Revision received May 31, 2017

Accepted June 13, 2017 